Procedure for Measuring and Reporting the Performance of Photovoltaic Systems in Buildings

S. Pless, M. Deru, P. Torcellini, and S. Hayter

Form

Pack

http://www.nrel.gov/docs/fy06osti/38603 fmpak.doc

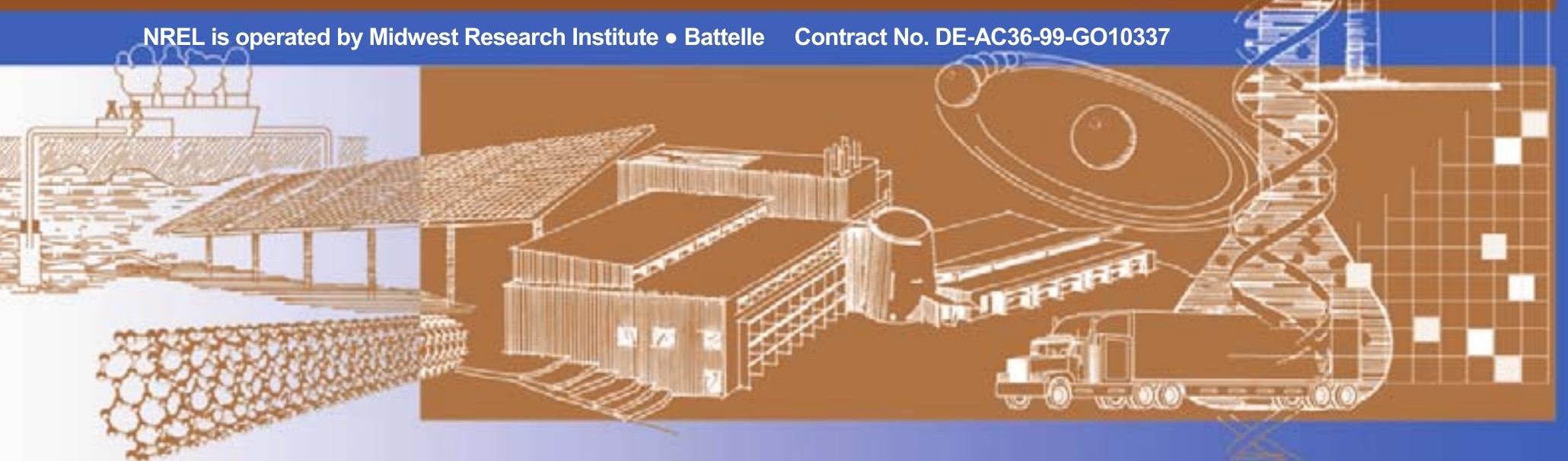




\section{Procedure for Measuring and Reporting the Performance of Photovoltaic Systems in Buildings}

Technical Report NREL/TP-550-38603

October 2005

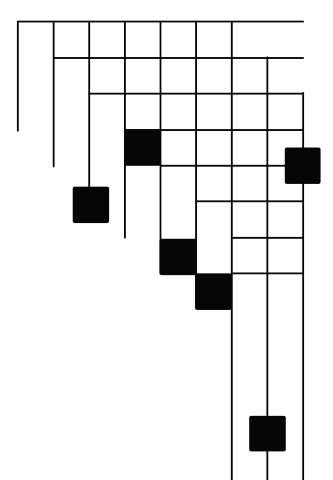




\section{NOTICE}

This report was prepared as an account of work sponsored by an agency of the United States government. Neither the United States government nor any agency thereof, nor any of their employees, makes any warranty, express or implied, or assumes any legal liability or responsibility for the accuracy, completeness, or usefulness of any information, apparatus, product, or process disclosed, or represents that its use would not infringe privately owned rights. Reference herein to any specific commercial product, process, or service by trade name, trademark, manufacturer, or otherwise does not necessarily constitute or imply its endorsement, recommendation, or favoring by the United States government or any agency thereof. The views and opinions of authors expressed herein do not necessarily state or reflect those of the United States government or any agency thereof.

Available electronically at http://www.osti.gov/bridge

Available for a processing fee to U.S. Department of Energy and its contractors, in paper, from:

U.S. Department of Energy

Office of Scientific and Technical Information

P.O. Box 62

Oak Ridge, TN 37831-0062

phone: 865.576 .8401

fax: 865.576 .5728

email: mailto:reports@adonis.osti.gov

Available for sale to the public, in paper, from:

U.S. Department of Commerce

National Technical Information Service

5285 Port Royal Road

Springfield, VA 22161

phone: 800.553.6847

fax: 703.605.6900

email: orders@ntis.fedworld.gov

online ordering: http://www.ntis.gov/ordering.htm

Printed on paper containing at least $50 \%$ wastepaper, including $20 \%$ postconsumer waste 


\section{DISCLAIMER AGREEMENT \\ (“Agreement")}

This document includes definitions, calculations and measurements of building energy use for use in energy performance analyses and is provided by the National Renewable Energy Laboratory ("NREL"), which is operated by the Midwest Research Institute ("MRI") for the U.S. Department of Energy ("DOE"). Access to and use of the information contained in this document shall impose the following obligations on the user, as set forth in this Agreement. The user is granted the right, without any fee or cost, to use, copy, modify, alter, enhance and distribute the information in this document for any purpose whatsoever, except commercial sales or other commercial purposes, provided that this entire notice appears in all copies of this document. Further, the user agrees to credit DOE/NREL/MRI in any publication that results from or includes any of the information contained in this document. The names DOE/NREL/MRI, however, may not be used in any advertising or publicity to endorse or promote any product or commercial entity unless prior specific written permission is obtained from the DOE/NREL/MRI. The user also understands that DOE/NREL/MRI is not obligated to provide the user with any support or assistance of any kind whatsoever with regard to the use of the information contained in this document or to provide the user with any updates, revisions or new versions of the information contained in this document.

YOU, THE USER, AGREE TO INDEMNIFY DOE/NREL/MRI, AND ITS SUBSIDIARIES, AFFILIATES, OFFICERS, AGENTS, AND EMPLOYEES AND HOLD THEM HARMLESS AGAINST ANY CLAIM OR DEMAND, INCLUDING REASONABLE ATTORNEYS' FEES, RELATED TO YOUR USE OF THE INFORMATION CONTAINED IN THIS DOCUMENT. THIS DOCUMENT, AND THE INFORMATION CONTAINED THEREIN ARE PROVIDED BY DOE/NREL/MRI "AS IS" AND ANY EXPRESS OR IMPLIED WARRANTIES, INCLUDING BUT NOT LIMITED TO, THE IMPLIED WARRANTIES OF MERCHANTABILITY AND FITNESS FOR A PARTICULAR PURPOSE ARE DISCLAIMED. IN NO EVENT SHALL DOE/NREL/MRI BE LIABLE FOR ANY SPECIAL, INDIRECT OR CONSEQUENTIAL DAMAGES OR ANY DAMAGES WHATSOEVER, INCLUDING BUT NOT LIMITED TO CLAIMS ASSOCIATED WITH AN ACTION IN CONTRACT, NEGLIGENCE OR OTHER TORTIOUS CLAIM THAT ARISES OUT OF OR IN CONNECTION WITH THE ACCESS, USE OR PERFORMANCE OF ANY OF THE INFORMATION CONTAINED IN THIS DOCUMENT. 


\section{Acknowledgments}

The authors want to thank the following individuals for reviewing this document: Drury Crawley, David Hansen, John Ryan (DOE), Michael McCabe (Navigant Consulting), Ed Hancock and Greg Barker (Mountain Energy Partnership), Jim Dunlop (FSEC), and John Westerman (SAIC). Additional thanks to NREL's National Center for Photovoltaics staff Cecile Warner, Byron Stafford, Mike Wassmer, Keith Emery, Peter McNutt, and Bill Marion for their comments and reviews. 


\section{Table of Contents}

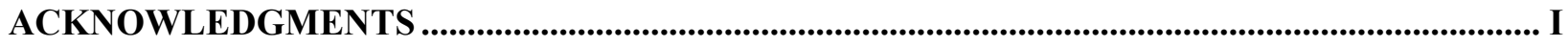

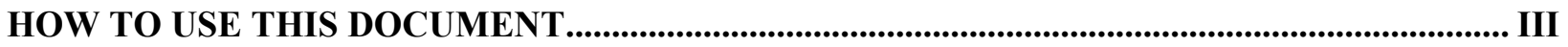

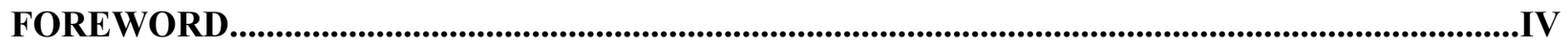

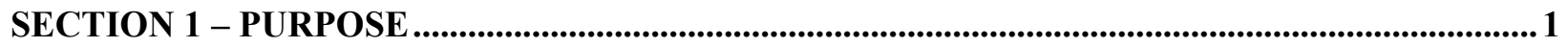

SECTION 2 - SCOPE

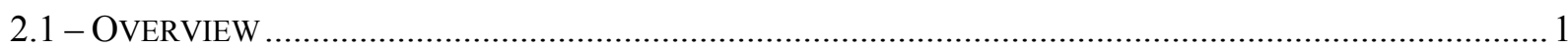

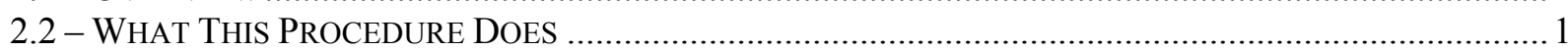

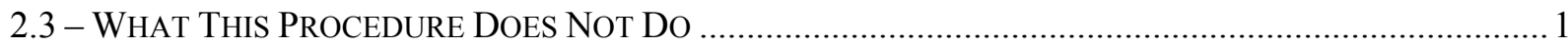

SECTION 3 - DEFINITIONS, ABBREVIATIONS, AND ACRONYMS......................................2

3.1 - GENERAL

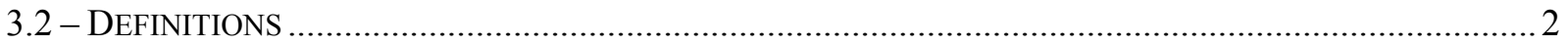

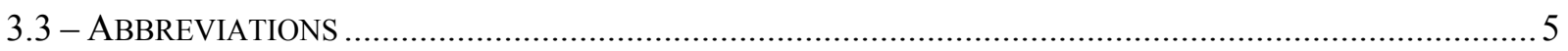

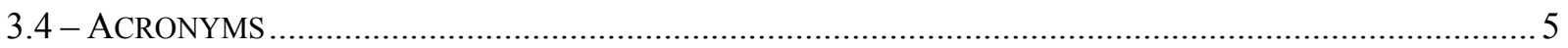

SECTION 4 - METRICS DETERMINED IN THIS PROCEDURE ...............................................

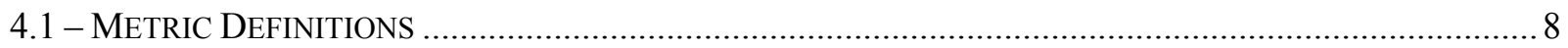

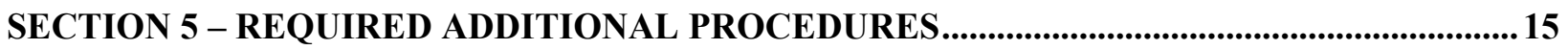

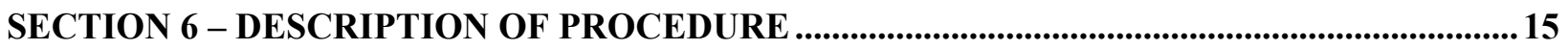

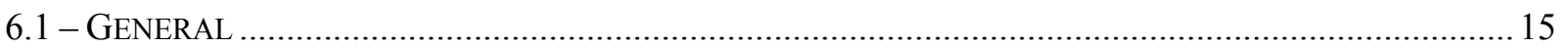

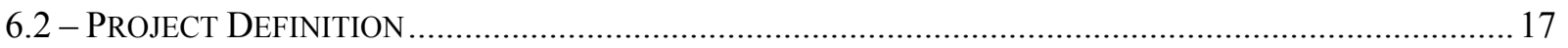

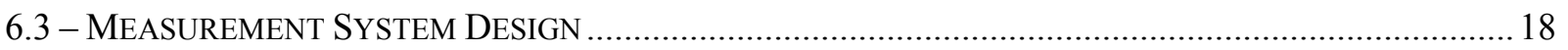

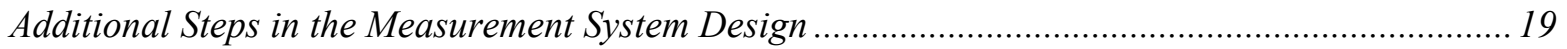

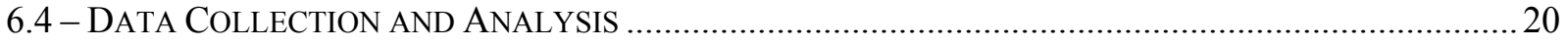

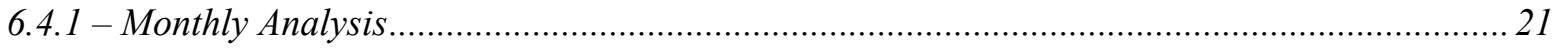

SECTION 7 - REPORTING FORMAT ...................................................................................................2 23

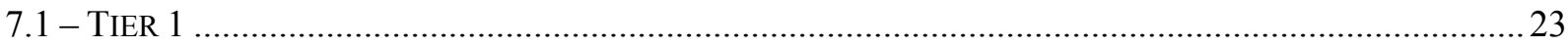

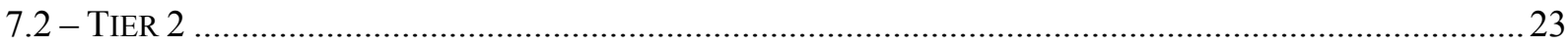

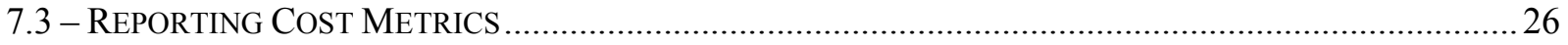

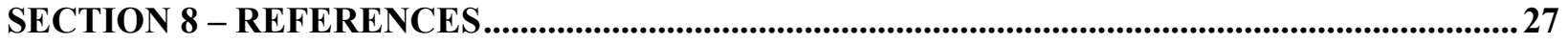

APPENDIX A - SAMPLE MEASUREMENT PLAN ..........................................................................29

APPENDIX B - DESCRIPTION OF MONITORING EQUIPMENT ................................................33

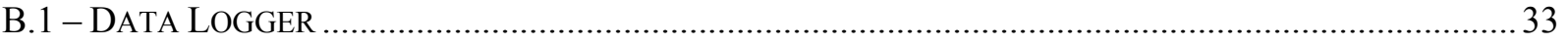

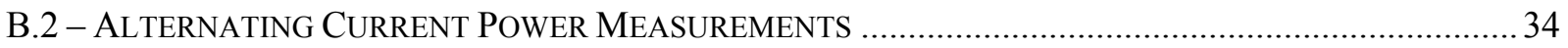

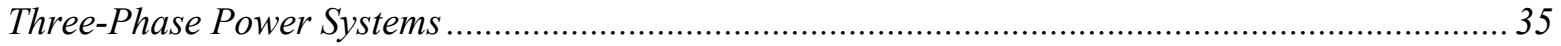

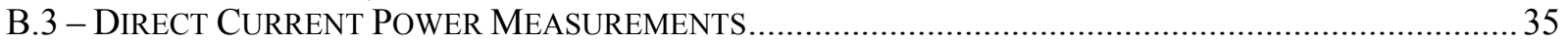

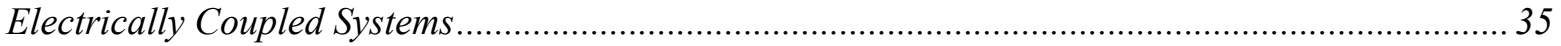

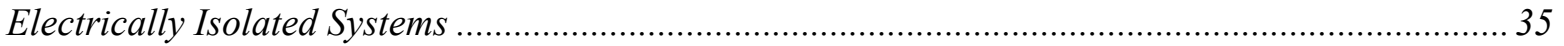

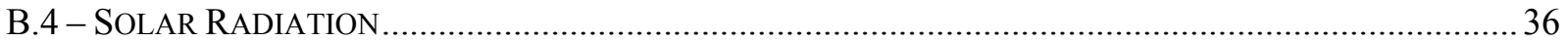

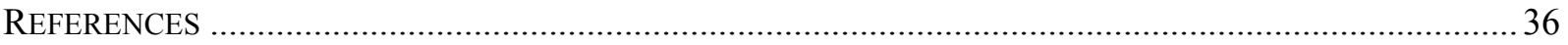




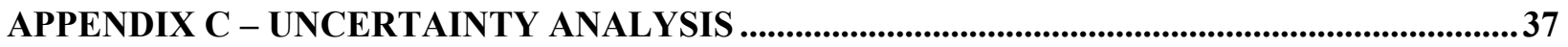

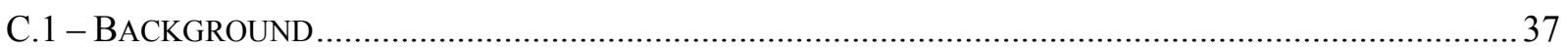

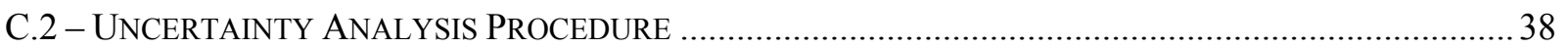

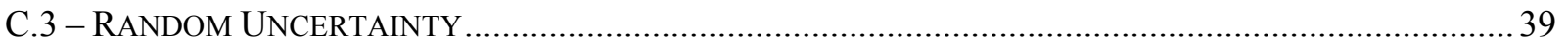

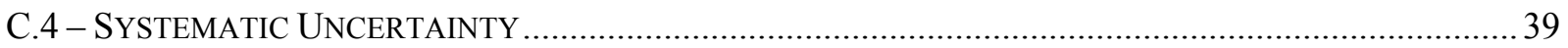

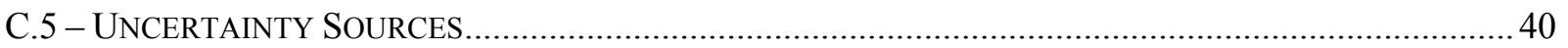

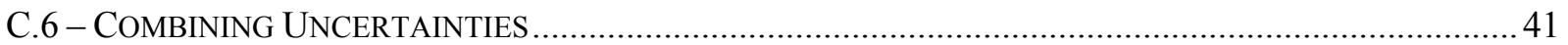

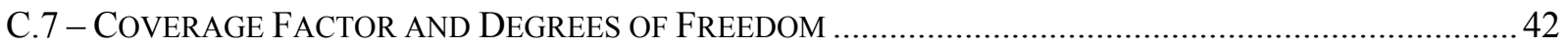

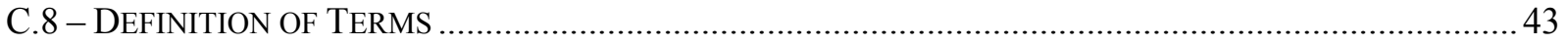

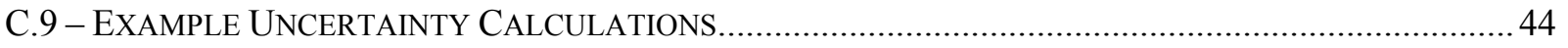

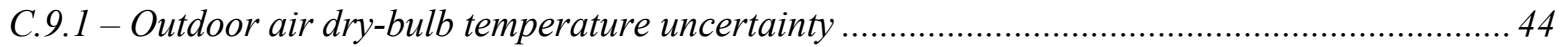

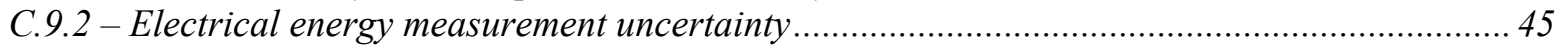

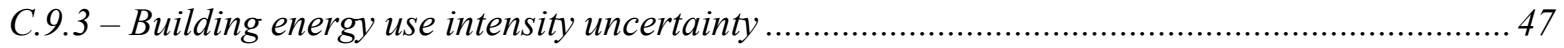

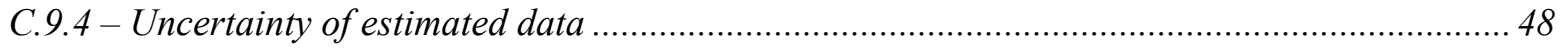

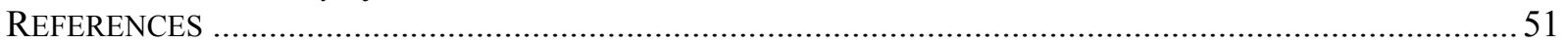

APPENDIX D - TYPE 2 GRID-TIED SYSTEM WITH BATTERY BACKUP ..............................52

\section{How to Use This Document}

Depending on the reader's purpose, the most efficient way to navigate this document may be something other than front to back. A quick reference guide is provided in the table below.

\section{Quick Reference Guide}

\begin{tabular}{|l|l|c|}
\hline Topic & Section(s) & Pages \\
\hline \hline How this procedure fits with the reader's purpose & Foreword, Purpose, Scope & iv-1 \\
\hline Definitions of the performance metrics & Section 4 & $7-15$ \\
\hline Summary overview of the procedure & Table 6-1 & 15 \\
\hline Description of Tier 1 and Tier 2 analyses & Section 6.2, Step I.D & 17 \\
\hline Step-by-step procedure, in detail & Section 6 & $15-20$ \\
\hline Definitions of terms and nomenclature & Section 3 & $2-5$ \\
\hline
\end{tabular}




\section{Foreword}

People measure and analyze the energy performance of buildings for many reasons. Comparisons of energy use may be made among nations, regions, individual buildings, or systems within a building. Policy makers, owners, designers, operators, raters, and researchers use energy performance data. Many tools (or approaches) have been developed to analyze energy performance in different ways, at different levels of effort and precision, and at different stages in the life of a building. Each tool quantifies the building energy performance to fit the users' needs. However, methods and metrics are often inconsistent with each other. In addition, performance numbers may be misrepresented or misused to predict energy savings beyond the accuracy of the numbers.

The Performance Metrics Project is a U.S. Department of Energy commercial buildings research activity whose goal is to standardize the measurement and characterization of building energy performance. Its main products are clearly defined energy performance metrics and standard procedures for determining the performance metrics; its intents are to define common language and to create standards that produce consistent results independently of the user. Therefore, the terms and techniques are clearly defined with little room for interpretation. The more opportunity there is for interpretation, the higher the probability for disparity and "gaming" of the results. These procedures focus on reporting absolute numbers and not on comparisons of energy performance. Benchmarks are included only where well-established values apply. However, benchmarking of results by others can be improved be using the clearly defined absolute metrics determined by these procedures.

Numerous other documents outline procedures for analyzing building and photovoltaic (PV) system energy performance. (See references in Section 8.) Some procedures are general and tend to outline the stages of project planning, management, and execution; they do not encompass the level of detail necessary to standardize specific measurements among buildings. On the other hand, the procedures that do encompass the necessary level of detail are not general enough to provide a standard basis of comparison among buildings. Stewart et al. (1984), in reviewing numerous energy audit procedures, commented:

Unfortunately, in the rush to account for energy usage, no cohesive pattern of auditing procedures was developed. Instead, a plethora of forms and procedures was prepared, often just for specific tasks. The result is the inability to compare the results of one audit to another with any sense of confidence.

Also, Misuriello (1987) commented, "The diverse nature of monitoring projects realistically precludes a universal protocol applicable to all monitoring efforts."

The Performance Metrics Project attempts to build on this body of work and resolve differences among the various approaches. The project has worked to address the following issues that have been problems with performance monitoring in the past:

- Standardization: Standard performance metrics provide a consistent basis for comparing energy performance among buildings.

- Versatility: The analysis is customized to the facility boundaries, energy configuration, analysis goals, and analysis budget that apply to a given project.

- Economy of Effort: The data collection is carefully matched to the goals of the analysis and the study questions to avoid the common pitfalls of too few or too many data.

Each procedure in this series outlines a measurement protocol that helps to quantify standard performance metrics. The primary users for whom these documents are intended are building energy analysts and technicians who design, install, and operate data acquisition systems (DAS), and who analyze and report 
building energy performance data. In addition, the Metrics Definitions in Section 4 of each procedure may be useful to others who interpret and apply such data.

Two levels of effort are outlined in these procedures to meet the needs of different users and to address the goals of versatility and efficiency in performance monitoring. In Tier 1, utility bills and other rapid, inexpensive means of data gathering are used to determine monthly and annual purchased energy, facility energy production, and related metrics. In Tier 2, submetering and an automated DAS system are used to determine subhourly time-series data. Tier 1 analysis is appropriate for the comparison of PV and building energy performance on an annual basis. A Tier 2 analysis can require a substantial effort; the benefits of this detailed study should be weighed against the associated costs.

Previous work has focused on rating the power output of PV systems and general performance monitoring. Rating system such as PVUSA (PG\&E 1995) apply a regression modeling technique combined with measured system performance and environmental conditions by calculating PV system power output at specific test conditions. A power equation method developed at NREL (Marion et.al. 1999) also rates PV power output at standard test conditions. An international standard (IEC 61724 1998) provides guidance on photovoltaic system monitoring, including specific performance indices. These existing PV rating methods and standards do not provide guidance on measuring and characterizing the long-term energy production of PV systems in buildings and the resulting impacts on a building's energy use and energy cost.

This procedure expands on previous work in this area by providing a standard method for measuring and characterizing the long-term energy performance of PV systems in buildings and the resulting implications to the building's energy use. The performance metrics determined here may be used for measuring:

- how much electricity the PV system produces,

- the percentage of the building's load that is met by PV production,

- the PV system's generation effectiveness,

- the reduction of building electrical demand resulting from the PV system, and

- the site energy expenditure savings accruing from the PV system.

This procedure does not offer guidance on diagnosing and detecting faults or provide direction for determining satisfactory measured performance or predicting expected performance. 


\section{Section 1 - Purpose}

The purpose of this procedure is to establish a standard method for monitoring and reporting on the performance of photovoltaic (PV) systems in buildings.

\section{Section 2 - Scope}

\section{1 - Overview}

This procedure provides a standard method for monitoring and reporting on the long-term performance of PV systems in buildings. The performance metrics determined here may be compared against benchmarks for evaluating system performance and verifying that performance targets have been achieved. Uses may include comparison of performance with the design intent; comparison with other PV systems in buildings; economic analysis of PV systems in buildings; and the establishment of longterm performance records that enable maintenance staff to monitor trends in energy performance. The procedure is applicable to the following types of commonly installed PV systems:

- Grid-tied PV systems with no battery storage (Type 1 system, Figure 4-1). These systems are connected to a building's utility grid through the building's electrical system.

- Grid-tied systems with battery storage, where the battery storage is part of either an uninterruptible power supply (UPS) (Type 2 system, Appendix D, Figure D-1) or integrated into the PV system and for other uses related to building energy use.

The procedure is divided into two tiers to differentiate the resolution of the results and the amount of effort that is typically required to complete the procedure. Tier 1 gives monthly and annual results for the system as a whole that are based primarily on utility meter readings or existing performance data. In addition to monthly and annual results, Tier 2 yields time-series results (typically 15- or 30-min data, corresponding to the electrical demand billing scheme) based on submetering and a data acquisition system (DAS).

\section{2 - What This Procedure Does}

The procedure may be used to evaluate the power supplied to a building's electrical system from a gridtied PV system and the implications to the building's energy use. It addresses only the renewable energy that the PV system converts to electrical power using the sunlight available to the PV system. The procedure encompasses grid-tied PV systems connected to all building types, including commercial, residential, and industrial buildings, and is intended for application after the PV system has been commissioned. The procedure includes definitions of the performance metrics obtained, detailed steps for quantifying performance, and a list of suggested monitoring equipment.

\section{3 - What This Procedure Does Not Do}

The procedure does not apply to PV systems where the power output is completely directed to any other use than the building, such as PV systems that power individual parking lot lights or path lighting. It does not address PV-hybrid systems, such as PV systems tied to a fossil fuel backup generator or wind generator, although portions of the procedure can be adapted to this use. The procedure does not address stand-alone (grid-independent) systems. It does not provide diagnostic support for identifying the reasons 
that systems are not performing as designed, nor does it give guidance on repair techniques or on predicting or determining satisfactory performance.

Although this procedure does include an analysis of electrical demand savings and associated cost savings, these results are not applicable to systems that include demand-limiting controls (see Section 4.1).

\section{Section 3 - Definitions, Abbreviations, and Acronyms}

\section{1 - General}

Terms, abbreviations, and acronyms defined in this section apply to this procedure. The names of performance metrics are defined in Section 4 and printed in bold type throughout this document. Terms, abbreviations, and acronyms not defined in either Section 3 or Section 4 are assumed to have their ordinary definitions in the context in which they are used, based on Standard American English.

\section{2 - Definitions}

Apparent Power

The product of the root mean square (RMS) volts and RMS amperes of a single phase circuit. This product divided by 1000 is designated in kilovolt-amperes $(\mathrm{kVA})$, and comprises both real and reactive power. Some utility rate structures include charges for peak demand based on apparent power.

Annual

A period that consists of 12 consecutive months.

Array Area

The total area of all the PV modules wired together under consideration, including the frames of the modules.

\section{Balance of System (BOS) Components}

All of the system components in a PV system, except the PV modules. The components include the structures, wiring, disconnects, current breakers, charge controllers, batteries associated with an uninterruptible power supply, isolation transformers, and inverters.

\section{Data Acquisition System (DAS)}

An automated data recording system that typically consists of a programmable data logger and numerous sensors for measuring energy use, environmental conditions, and other measurements needed to complete Tier 2 of this procedure. The recording interval should correspond to the applicable electrical demand-billing scheme, if applicable (typically 15- or 60-min data), so that the data enable demand-reduction strategies to be analyzed after the procedure is completed. (See also the definition of time series.) The system should be operated and the data collected for at least 1 year to allow seasonal trends and annual totals to be determined with this procedure.

Demand-Responsive Control

A building demand controller that limits electrical demand when the prices of electricity are high. Noncritical loads, such as fans and lights, can be controlled to reduce monthly peak demands. 
Facility

A set of one or more buildings or outdoor applications, or both, that use energy and share a common utility meter. If there is a compelling reason to apply a different boundary to the analysis, that boundary and the reasons for using it should be clearly described in the report.

\section{Grid-Tied PV System}

A PV system that is electrically linked to the electrical utility grid. The PV system may be integrated with the building envelope, mounted on the building structure, or separated from the building, and may or may not include battery storage.

\section{Incident Solar Radiation}

The flux of solar radiation (irradiance) in the plane of the array per unit area averaged over the timeseries interval (in watts per square meter $\left[\mathrm{W} / \mathrm{m}^{2}\right]$ ).

\section{Measure}

To determine a quantity with a calibrated instrument. This includes using previously measured data such as those shown on a utility bill or engineering log.

Metric

A standard definition of a measurable quantity. (See examples of performance metrics in Section 4.1.)

Month

A calendar month, or a utility billing period of similar duration.

\section{Performance Metric}

A standard definition of a measurable quantity that indicates some aspect of performance. Section 4 contains definitions of the specific performance metrics used in this procedure.

\section{Photovoltaic Module}

A complete, environmentally protected unit consisting of solar cells, optics, and other components, exclusive of tracker, designed to generate DC power when exposed to sunlight (National Electric Code [NEC] 2002).

Photovoltaic System

A photovoltaic system includes the photovoltaic modules wired together in series and parallel in an array and the associated BOS components.

\section{Power Factor}

The ratio of real power (in kilowatts [kW]) to apparent power (in kVA) at any given point and time in an electrical circuit. Generally, this is expressed as a percentage ratio.

Procedure

A standard technique for determining one or more performance metrics, or a document (such as this one) that outlines such technique(s). 


\section{Rated PV Capacity}

The sum of the peak rated DC power output of all the PV modules in the PV system at standard test conditions, expressed as peak rated watt $\left(\mathrm{W}_{\mathrm{p}}\right)$ or kilowatt $\left(\mathrm{kW}_{\mathrm{p}}\right)$.

\section{Rated PV Module Efficiency}

The efficiency of the PV modules in a PV system to convert incident solar radiation to electricity at standard test conditions. Generally determined by dividing the rated PV capacity by the product of the array area and the incident solar radiation at standard test conditions $\left(1000 \mathrm{~W} / \mathrm{m}^{2}\right)$. For example, the rated PV module efficiency of a PV module rated at $85 \mathrm{~W}$ with an array area of $0.63 \mathrm{~m}^{2}$ can be determined by: $85 \mathrm{~W} /\left(0.63 \mathrm{~m}^{2} \cdot 1000 \mathrm{~W} / \mathrm{m}^{2}\right)=13.5 \%$

\section{Reactive Power}

The portion of Apparent Power that does no work. It is commercially measured in kilovars (kVAR). Reactive power must be supplied to most types of magnetic equipment, such as motors.

\section{Real Power}

The energy or work-producing part of Apparent Power. The rate of supply of energy, measured commercially in kilowatts. The product of the real power (product of instantaneous voltage and current in a single phase circuit) and length of time is energy, measured with watt-hour meters and expressed in kilowatt-hours $(\mathrm{kWh})$.

\section{Standard Test Conditions}

The fixed set of conditions for which PV module performance is rated. These conditions are 1000 $\mathrm{W} / \mathrm{m}^{2}$ incident solar radiation, $25^{\circ} \mathrm{C}$ cell temperature, 0.0 wind speed, and Air Mass 1.5 spectrum (ASTM 1996). While these standard test conditions are convenient for measuring module output in a laboratory setting for ratting purposes, they do not represent actual operating conditions. The actual cell temperature is much lower at standard test conditions in the laboratory than will typically be seen in the field.

\section{Standby Operation}

The PV system operation mode during which there is no usable AC PV electricity production. System inefficiencies, such as parasitic transformer losses, can result in substantial standby energy use during this mode of operation.

Tier

A portion of a procedure that is categorized in terms of (1) the resolution of the results obtained and (2) the level of effort typically required to obtain the results. (See Section 6.2, Step I.D, for further explanation.) The particular performance metrics determined in each of the two tiers in this procedure are diagrammed in Section 4 and tabulated in Section 6.

Tier 1

The most basic level of a procedure, which yields high level results. General characteristics of Tier 1 are that it (1) generally yields only monthly and annual results; (2) often requires only existing data, including utility bills, building drawings, and a physical examination (walk-through) of the building; and (3) is typically performed without installing additional metering equipment. A dedicated AC PV production meter may be required in tier 1 if no other means to determine PV production are available. 
Tier 2

The advanced level of a procedure, which yields more detailed results. Most analysts who are interested in a detailed examination of a building's performance will perform a Tier 2 analysis. General characteristics of Tier 2 are that it (1) yields seasonal, daily, hourly, or subhourly (if appropriate) results; (2) yields results itemized by type of end use; and (3) requires new data to be recorded in addition to existing building data. Submetering and a DAS are generally employed.

\section{Time Series}

The data-recording interval that corresponds to the applicable electrical demand-billing scheme (typically 15 - or 60-min data). If there is no applicable electrical demand-billing scheme, the recording interval should be based on any interest in using the data to analyze demand-reduction strategies. ${ }^{1}$

\section{Uninterruptible Power Supply (UPS)}

A backup power supply that is designed to provide power to a site in the event of interruptions in the incoming (grid) electrical power.

\section{Utility}

An organization responsible for the installation, operation, and maintenance of the supply of a public service (such as electricity, natural gas, or water) to a specific site.

\section{3 - Abbreviations}

$\begin{array}{ll}\text { BTU/day } & \text { British thermal units per day } \\ \text { BTU/month } & \text { British thermal units per month } \\ \text { BTU/yr } & \text { British thermal units per year } \\ \mathrm{kVA} & \text { kilovolt-amperes } \\ \mathrm{kVAR} & \text { kilovars } \\ \mathrm{kW} & \text { kilowatts } \\ \mathrm{kWh} & \text { kilowatt-hours } \\ \mathrm{kWh} / \text { day } & \text { kilowatt-hours per day } \\ \mathrm{kWh} / \mathrm{month} & \text { kilowatt-hours per month } \\ \mathrm{kWh} / \mathrm{yr} & \text { kilowatt-hours per year } \\ \mathrm{W} / \mathrm{m}^{2} & \text { watts per square meter }\end{array}$

\section{4 - Acronyms}

AC Alternating current

ASHRAE American Society of Heating, Refrigerating, and Air-conditioning Engineers

BAS Building automation system

BOS Balance of system

CT Current transformer

DAS Data acquisition system (see definition in Section 3.2)

DC Direct current

EIA Energy Information Administration

IC Integrated circuit

\footnotetext{
${ }^{1}$ Synchronizing the analysis to the time base used by the utility company can be difficult. Thus, values of peak demand determined by monitoring may differ from those shown on the electric bill. Nonetheless, the data are useful for analyzing load management opportunities as an adjunct to this procedure.
} 
IPMVP International Performance Measurement and Verification Protocol

NEC National Electric Code

NREL National Renewable Energy Laboratory

O\&M Operations and maintenance

PV Photovoltaic

RMS Root mean square

TC Thermocouple

UPS Uninterruptible power supply 


\section{Section 4 - Metrics Determined in This Procedure}

The procedure is divided into two tiers to differentiate the resolution of the results and the amount of effort required to complete the procedure. The Tier 1 metrics that can be measured, with existing data, are shown in Appendix A, Figure A-2. Tier 2 metrics that can be measured and the required data are shown in Appendix A, Figure A-3. The Tier 1 procedure provides monthly and annual results for the system as a whole from utility bills or other forms of pre-existing PV system performance data. An example of a Tier 1 analysis would be if an owner/operator were interested in verifying design predictions of PV system production as compared to site energy use on a monthly or annual basis. Pre-existing data and monthly utility bills would be used for this Tier 1 analysis.

If the appropriate monitoring equipment or performance data are not available, then Tier 1 metrics can only be determined by following the Tier 2 procedures. The Tier 2 procedure provides results based on time-series data, in addition to monthly and annual results. Tier 2 results are based on data from a data acquisition system with submetering. Tier 2 metrics can also include and expand Tier 1 results from utility bills. An example of a Tier 2 analysis would be to determine the hourly AC generation effectiveness for calculating availability statistics. Tier 1 and Tier 2 procedures for determining the metrics defined below are described in Section 6.

Figure 4-1 shows the location of the primary metric measurement locations for a typical PV system connected to the utility grid through a building's electrical system. Table 4-1 provides the names of the primary metrics shown in Figure 4-1. Appendix D details a similar system that includes a UPS system (Type 2).

PV System

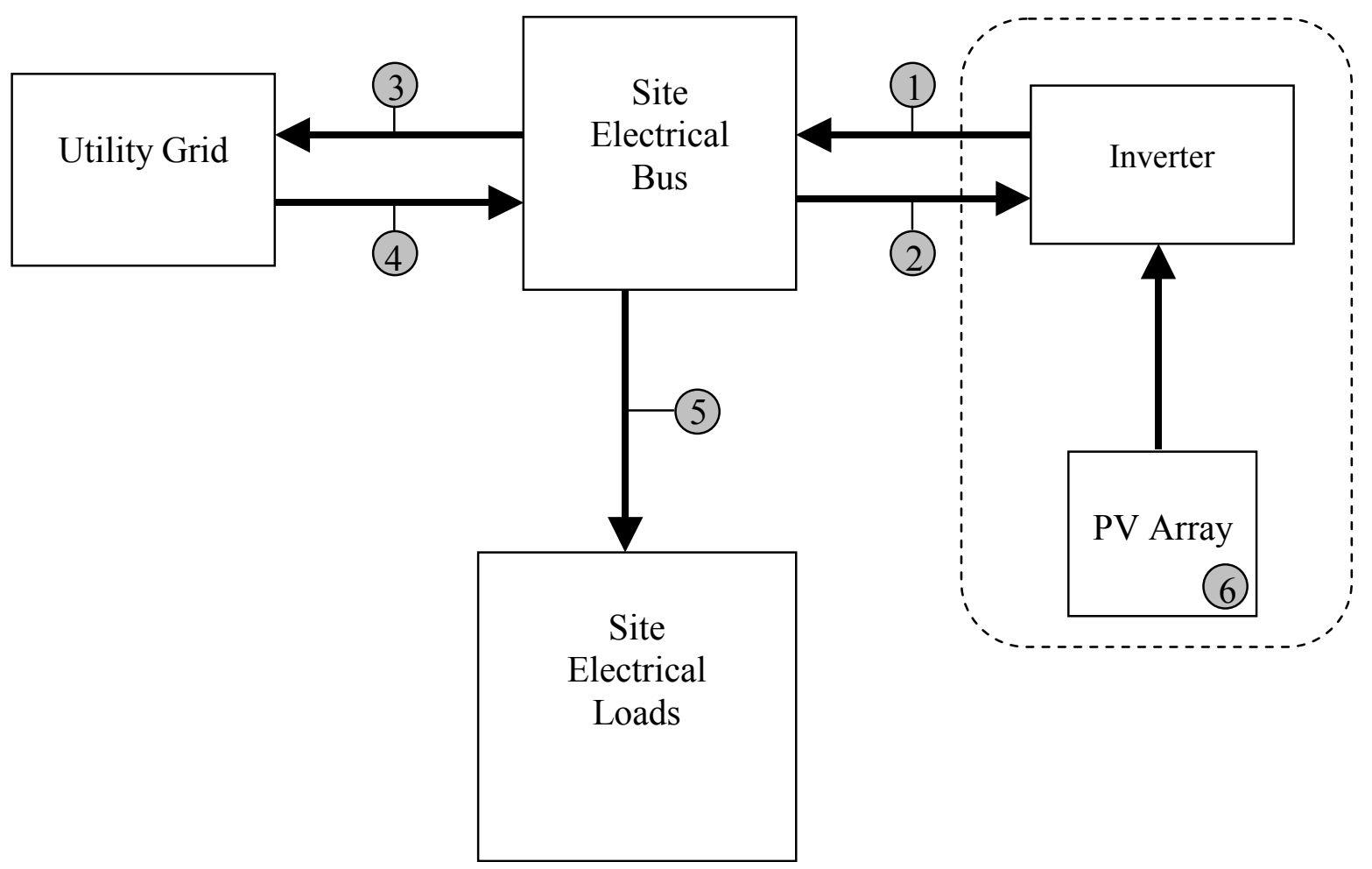

Figure 4-1 Metric measurement locations for grid-connected Type 1 PV system 
Table 4-1 Metrics in Figure 4-1

\begin{tabular}{|l|l|}
\hline Meter \# & \multicolumn{1}{|c|}{ Metric and Labels } \\
\hline \hline 1 & Total PV System AC Production \\
\hline 2 & PV System Standby Use \\
\hline 1 minus 2 & Net PV System Production \\
\hline 3 & Total Electricity Delivered To the Utility \\
\hline 4 & Total Electricity Consumed From the Utility \\
\hline 4 minus 3 & Net Facility Electricity Use \\
\hline 5 & Total Facility Electricity Use \\
\hline 6 & Incident Solar Radiation \\
\hline
\end{tabular}

In a net-metering configuration that includes a single bi-directional utility meter capable of metering electricity use (meter 4 from Figure 4-1) and electricity sold back to the utility (meter 3 from Figure 4-1), separate meters of electricity supplied by the utility and delivered to the utility are not necessary. Meter 3 and 4 in Figure 4-1 will be a single meter, but still measure the Net Facility Electricity Use.

\section{1 - Metric Definitions}

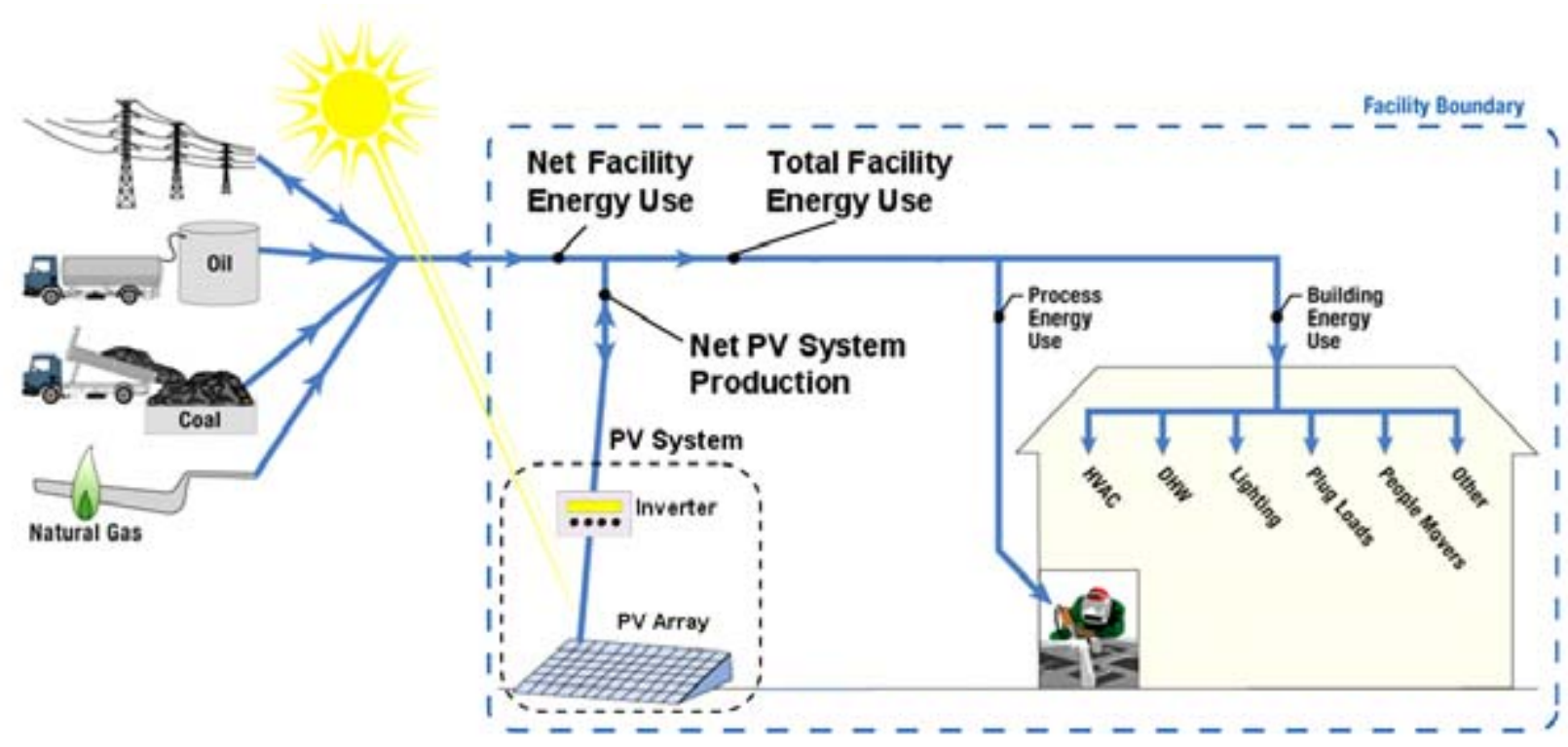

Figure 4-2 Energy flow diagram for PV systems in buildings

The energy flow diagram provided in Figure 4-2 shows the highest level metrics determined in this procedure. Metrics determined in this procedure are organized based on how they relate to the PV system (Net PV System Production), the facility (Total Facility Energy Use), or the affect of the PV system on the facility (Net Facility Energy Use). The highest level metrics and related metrics are shown in Table 4-2. 
Table 4-2 High-Level and Related Metrics

\begin{tabular}{|l|l|}
\hline $\begin{array}{l}\text { High-Level } \\
\text { Metrics }\end{array}$ & \multicolumn{1}{c|}{ Related Metrics } \\
\hline & $\begin{array}{l}\text { Total PV System Production } \\
\text { PV System Standby Use } \\
\text { Equivalent Daily Hours of Peak Rated PV Production } \\
\text { Equivalent Annual Hours of Peak Rated PV Production } \\
\text { System } \\
\text { Production } \\
\text { Total Incident Solar Radiation } \\
\text { PV System AC Electricity Generation Effectiveness } \\
\text { PV System Performance Ratio } \\
\text { Maximum Time-Series Net PV Production } \\
\text { Average Daily Time-Series PV Production Profiles }\end{array}$ \\
\hline $\begin{array}{l}\text { Total } \\
\text { Facility } \\
\text { Energy Use }\end{array}$ & $\begin{array}{l}\text { Total Facility Electricity Use } \\
\text { Peak Demand of Total Facility Electricity Use without PV System } \\
\text { Facility Electricity Costs without PV System }\end{array}$ \\
\hline \multirow{2}{*}{$\begin{array}{l}\text { Fet Facility } \\
\text { Energy Use }\end{array}$} & $\begin{array}{l}\text { Facility's Electrical Load Offset by PV Production } \\
\text { Total Electricity Delivered to Utility } \\
\text { Peak Demand of Net Facility Electricity Use } \\
\text { Reduction of Peak Demand Resulting from the PV system } \\
\text { Facility Electricity Costs } \\
\text { Energy Cost Savings Accruing from PV System }\end{array}$ \\
\hline
\end{tabular}

The performance metrics that can be determined through this procedure are defined as follows.

\section{Total PV System Production}

The total electricity produced by the PV system and directly used in facility loads, or exported to the utility grid. If utility bills or pre-existing data are available that provides sufficient data for meter 1 from Figure 4-1, this metric is measurable in Tier 1. If no pre-existing performance data are available, this metric is determined through Tier 2 procedures.

Reported as: monthly totals, annual totals, and average daily totals per month

Units: $\mathrm{kWh} /$ month, $\mathrm{kWh} / \mathrm{yr}, \mathrm{kWh} /$ day

\section{PV System Standby Use}

Some electrical components integral to the PV system - including the inverter, the battery bank, and the isolation transformer-have parasitic electrical use loads during system standby operation. These losses do not include system inefficiencies during normal production. If the PV system does not include components that have parasitic loads, or pre-existing data are available, then this metric can be determined in Tier 1. The monthly and annual standby use of the PV system can be estimated or directly measured as a Tier 2 metric. An estimate for meter 2 from Figure 4-1 can be based on a one-time handheld measurement taken at night. The manufacturer's nameplate standby energy use can be used along with the expected time of standby operation, although accuracy is sacrificed with this approach. A direct time-series measurement is recommended for better accuracy. 
Reported as: monthly and annual totals

Units: $\mathrm{kWh} / \mathrm{month}, \mathrm{kWh} / \mathrm{yr}$

\section{Net PV System Production}

The net electricity produced by the PV system and delivered to facility loads or exported to the grid, accounting for PV system parasitic losses during standby operation. This metric is represented by meter 1 minus meter 2 in Figure 4-1. If utility bills or pre-existing data is available at meter 1 and meter 2 from Figure 4-1, this metric can be estimated in Tier 1. If PV System Standby Use and Total PV System Production metrics are not determined as Tier 1 metrics, this metric is determined through Tier 2 metrics.

Reported as: monthly totals, annual totals, and average daily totals per month

Units: $\mathrm{kWh} / \mathrm{month}, \mathrm{kWh} / \mathrm{yr}, \mathrm{kWh} /$ day

Calculated by: Total PV System Production - PV System Stand By Use

\section{Equivalent Daily Hours of Peak Rated PV Production}

The daily PV production normalized by rated PV capacity for each month.

Reported as: monthly average hours per day per rated PV capacity

Units: hrs/day per $\mathrm{kW}_{\mathrm{p}}$ of rated capacity

Calculated by: $\frac{\text { Net PV System Production }(\mathbf{k W h} / \mathbf{d a y})}{\text { Rated PV Capacity }\left(\mathrm{kW}_{\mathrm{p}}\right)}$

\section{Equivalent Annual Hours of Peak Rated PV Production}

The annual PV production normalized by rated PV capacity.

Reported as: annual thousands of hours per year per rated PV capacity

Units: $1000 \mathrm{hrs} / \mathrm{yr}$ per $\mathrm{W}_{\mathrm{p}}$ of rated capacity

Calculated by: $\frac{\text { Net PV System Production }(\mathbf{k W h} / \mathbf{y r})}{\text { Rated PV Capacity }\left(\mathrm{W}_{\mathrm{p}}\right)}$

\section{Total Facility Electricity Use}

The monthly and annual total electricity consumed at the facility. As a Tier 1 metric, it can be measured if pre-existing performance data or utility bills facilitate the calculation. For example, if the utility bill includes the monthly net electricity purchased from the utility (meter 4 minus meter 3 in Figure 4-1), and monthly Net PV System Production is available (meter 1 minus meter 2 in Figure 4-1), calculate the Total Facility Electricity Use by adding the Net PV System Production to the net energy purchased from the utility. This metric is represented by meter 5 in Figure 4-1.

Reported as: monthly totals, annual totals, and average daily totals per month 
Units: $\mathrm{kWh} /$ month, $\mathrm{kWh} / \mathrm{yr}, \mathrm{kWh} /$ day

Calculated by: Net PV System Production + net energy purchased from the utility

\section{Total Facility Energy Use}

The monthly and annual total energy consumed at the facility. This metric is used to compare the facility energy use to PV production. A zero-energy (site) building produces more energy than is used, resulting in $100 \%$ or greater total facility energy use met by the PV system. The total facility nonelectrical energy use can generally be obtained from utility bills and fuel supplier invoices.

Reported as: monthly totals, annual totals, and average daily totals per month

Units: $\mathrm{kWh} / \mathrm{month}, \mathrm{kWh} / \mathrm{yr}, \mathrm{kWh} / \mathrm{day}$, and BTU/month, BTU/yr, BTU/day

Calculated by: Total Facility Electricity Use + Total Facility Nonelectrical Energy Use

\section{Facility Electrical Load Offset by PV Production}

The net electricity produced by the PV system compared to the Total Facility Electricity Use.

Reported as: percentage of annual and monthly electrical facility load met by PV system.

Units: nondimensional value expressed as a percentage

$$
\text { Calculated by: }\left(\frac{\text { Net PV System Production }(\mathrm{kWh} / \mathrm{month}, \mathrm{kWh} / \mathrm{yr})}{\text { Total Facility Electricity Use }(\mathrm{kWh} / \mathrm{month}, \mathrm{kWh} / \mathrm{yr})}\right) \cdot 100 \%
$$

\section{Facility Total Energy Load Met by PV Production}

The net electricity produced by the PV system compared to the Total Facility Energy Use. A building that produces more energy than it uses would result in $100 \%$ or greater total facility energy load met by the PV system.

Reported as: percentage of annual and monthly total facility energy load met by PV system.

Units: nondimensional value expressed as a percentage

Calculated by: $\left(\frac{\text { Net PV System Production }(\mathrm{kWh} / \mathrm{month}, \mathrm{kWh} / \mathrm{yr})}{\text { Total Facility Energy Use }(\mathrm{kWh} / \mathrm{month}, \mathrm{kWh} / \mathrm{yr})}\right) \cdot 100 \%$

\section{Total Electricity Delivered to Utility}

When the PV system produces more AC electricity than is used at the facility, the excess production typically will be exported to the utility grid. This metric is represented by meter 3 in Figure 4-1. In a netmetering agreement, this metric is typically measured by the utility to determine the financial credit to the building and PV system. 
Reported as: monthly and annual total electricity that is exported to the utility grid

Units: $\mathrm{kWh} / \mathrm{month}, \mathrm{kWh} / \mathrm{yr}$

\section{Total Incident Solar Radiation}

The solar radiation in the plane of the solar array. It is calculated by summing the time-series solar radiation flux per unit area and multiplying by the PV array area. The location of this metric is represented by meter 6 in Figure 4-1.

Reported as: annual and monthly total incident solar radiation

Units: $\mathrm{kWh} / \mathrm{yr}, \mathrm{kWh} / \mathrm{month}$

Calculated by:

Total Incident Solar Radiation $\left(\mathrm{kWh} / \mathrm{m}^{2} / \mathrm{month}, \mathrm{kWh} / \mathrm{m}^{2} / \mathrm{yr}\right) \cdot \mathrm{PV}$ Array Area $\left(\mathrm{m}^{2}\right)$

\section{PV System AC Electricity Generation Effectiveness}

The time-series, monthly, and annual effectiveness of the PV system in converting incident solar resources to AC electricity used in the building or exported to the grid. The time-series effectiveness is determined for each time step and then plotted in a scatter plot versus Total Incident Solar Radiation to show performance on an interval basis. See Figure 7.3 for an example plot.

Reported as: 1. Monthly and annual average effectiveness

2. Plot of time-series generation effectiveness versus insolation

Units: nondimensional value expressed as percent effectiveness

$$
\begin{aligned}
\text { Calculated by: } & \text { 1. }\left(\frac{\text { Net PV System Production }(\mathrm{kWh} / \mathrm{month}, \mathrm{kWh} / \mathrm{yr})}{\text { Total Incident Solar Radiation }(\mathrm{kWh} / \mathrm{month}, \mathrm{kWh} / \mathrm{yr})}\right) \cdot 100 \% \\
& \text { 2. }\left(\frac{\text { Time - series Net PV System Production }(\mathrm{kW})}{\text { Time - series Total Incident Solar Radiation }(\mathrm{kW})}\right) \cdot 100 \%
\end{aligned}
$$

\section{PV System Performance Ratio}

The ratio of the daily, monthly, and annual PV System AC Electricity Generation Effectiveness to the rated PV module efficiency. The Performance Ratio is a PV system metric that is normalized by both PV system capacity and incident solar radiation. The Performance Ratio can indicate the overall effect of losses on the rated PV capacity due to system inefficiencies such as cell temperature effects, BOS faults, and system downtime. An idealized Performance Ratio of 1.0 would imply the PV system operated at standard test conditions over the reported period, without any BOS losses.

Reported as: 1. Daily, monthly, and annual average performance ratio

2. Plot of daily performance ratio (see Figure 7.4 for example plot)

Units: nondimensional value expressed as a performance ratio 
Calculated by: $\left(\begin{array}{c}\begin{array}{c}\text { PV System AC Electricity Generation Effectiveness } \\ \text { (daily } \%, \text { monthly } \%, \text { yearly } \%)\end{array} \\ \text { rated PV module efficiency (\% at standard test conditions) }\end{array}\right)$

\section{Net Facility Electricity Use}

The monthly electricity purchased from the utility. It is obtained from the monthly utility bills or from the monthly sum of the time-series Net Facility Electricity Use. A single watt-hour meter can be used if the meter is capable of monitoring bi-directional electricity flow. In a net-metering configuration that includes a single bidirectional utility meter capable of metering electricity use (meter 4 from Figure 4-1) and electricity sold back to the utility (meter 3 from Figure 4-1), separate meters of electricity supplied by the utility and delivered to the utility are not necessary. Meter 3 and 4 in Figure $4-1$ will be a single meter, but still measure the Net Facility Electricity Use. If the utility rate schedule is based on peak real power (in kilowatts), the time-series purchased energy meter should measure real power. If the utility rate structure includes a charge for apparent power (in $\mathrm{kVA}$ ) or power factor charges, then the time-series purchased energy meter should measure both real and apparent power. This metric is represented by meter 4 minus meter 3 in Figure 4-1.

Reported as: monthly and annual net Electricity Use

Units: $\mathrm{kWh} / \mathrm{month}, \mathrm{kWh} / \mathrm{yr}$

\section{Peak Demand of Net Facility Electricity Use}

The monthly peak use of the Net Facility Electricity Use. It is obtained from the monthly utility bills, as defined in the applicable electric utility rate structure, or from the monthly peak of the time-series Net Facility Electricity Use. If the utility rate charges based on peak real power (in kilowatts), the timeseries purchased energy meter should measure real power. If the utility rate schedules are based on apparent power (in kVA) or if they consist of power factor charges, the time-series Net Facility Electricity Use meter should measure both real and apparent power.

Reported as: monthly peak demand of Electricity Use, annual maximum of monthly values

Units: peak $\mathrm{kW} /$ month or peak $\mathrm{kVA} /$ month, corresponding to electric utility rate structure

\section{Peak Demand of Total Facility Electricity Use without PV System}

The monthly peak of the Total Facility Electricity Use. This metric represents what the peak facility demand would be if the PV system were not integrated into the building's electrical system. It is obtained from the monthly peak of the time-series Total Facility Electricity Use. If the utility rate charges are based on peak real power (in kilowatts), the time-series electricity use meter should measure real power. If the utility rate schedules are based on apparent power (in $\mathrm{kVA}$ ) or if they consist of power factor charges, this time-series electricity use meter should measure both real and apparent power. This metric is not directly measurable if the building electrical system features demand-responsive controls.

Reported as: monthly peak demand of electricity use without PV system, annual maximum of monthly values

Units: peak $\mathrm{kW} /$ month or peak $\mathrm{kVA} /$ month, corresponding to electric utility rate structure 
If a building does feature demand-responsive controls, it is not possible to measure the demand savings afforded by the controls. These savings cannot be measured because there is no way to measure what the building load would have been without the controls. In addition, if the building also features a PV system, the controls interact with the PV system in a way that makes it impossible to measure their effects separately. To estimate the demand savings resulting from a PV system in a building with demandresponsive controls, a building energy simulation tool is needed. The model used must be capable of (1) time-series simulation using the same time step that applies in the utility demand rate structure, and (2) analysis of the building's electrical load with and without the controls and the PV system. Details of such simulation analysis are not described in this procedure.

\section{Reduction of Peak Demand Resulting from the PV system}

The monthly peak demand reduction that resulted from the PV system supplying AC electricity to the facility. If a building electrical system does not feature demand-responsive controls, it is possible and straightforward to measure the demand reduction afforded by the PV system.

Reported as: monthly demand reduction resulting from PV system

Units: $\mathrm{kW}$ or $\mathrm{kVA}$

Calculated by: Monthly values of:

\section{Peak Demand of Total Facility Electricity Use without PV System (kW or kVA) - Peak Demand of Net Facility Electricity Use (kW or kVA)}

\section{Facility Electricity Costs}

The electricity costs reported on the monthly electrical utility bills. Use this metric to calculate the PV system cost savings metric.

Reported as: monthly and annual facility electricity costs

Units: \$/month, $\$ / y r$

\section{Facility Electricity Costs without PV System}

The facility electricity costs if there was not a PV system integrated into the building's electrical system. Use this metric when calculating the Energy Cost Savings Resulting from PV System metric. Calculate this metric by applying the utility rate structure to the time-series Total Facility Electricity Use. Applicable demand (in kilowatts or kVA), use, block, distribution, ratchets, taxes, and time-of-use charges are applied to the facility electricity use to calculate what the utility costs would have been without the PV system.

Reported as: monthly and annual facility electricity costs without PV system

Units: \$/month, $\$ / y r$ 


\section{Energy Cost Savings Resulting from PV System}

The energy cost savings that are a result of the PV system supplying useful electricity to the building. The energy cost savings is the difference between the calculated energy costs without the PV system and the actual utility bills.

Reported as: monthly and annual facility electricity costs savings accruing from PV system

Units: $\$ /$ month, $\$ / y r$

Calculated as: Facility Electricity Costs without PV System - Facility Electricity Costs

\section{Maximum Time-Series Net PV Production}

The time-series Net PV System Production peak for a particular month and annually. The maximum production can provide an indication of the PV system performance at peak solar conditions. This maximum is not the maximum instantaneous power; instead, it is the maximum power averaged over the time-series interval.

Reported as: monthly and annual maximum PV production

Units: peak $\mathrm{kW} /$ month, peak $\mathrm{kW} / \mathrm{yr}$

\section{Average Daily Time-Series PV Production Profiles}

The time-series Net PV System Production monthly and annual average daily profiles. These profiles indicate seasonal changes of the PV system performance over annual variations in solar conditions.

Reported as: twelve monthly average daily profile graphs and one annual average daily profile graph. See Figure 7.2 for an example plot.

Units: $\mathrm{kW}$ vs. time of day

\section{Section 5 - Required Additional Procedures}

No other procedures are required to complete this procedure. However, the Procedure for Measuring and Reporting Commercial Building Energy Performance (Barley, et al. 2005) contains similar site performance metrics that are used to evaluate building performance.

\section{Section 6 - Description of Procedure}

\section{1 - General}

This section describes the recommended step-by-step procedure for planning and completing an analysis of PV systems in buildings, yielding measured values of the metrics defined in Section 4. An overview of the procedure is outlined in Table 6-1. Explanations of each step are provided in the sections indicated in the outline. This procedure is specifically designed to address the following issues: 
- Standardization. The performance metrics defined in Section 4 form a consistent basis for comparing energy performance among systems.

- Versatility. The analysis is customized to the site boundaries, system configuration, analysis goals, and analysis budget that apply to the project.

- Efficiency. The data collection is carefully matched to the goals of the analysis and the study questions, avoiding the common pitfalls of too little or too much data.

\section{Table 6-1 Procedure Flow Chart}

\section{Project Definition (Section 6.2)}

A. Identify project goals.

B. List specific questions to be answered.

C. Determine boundaries of the site to be analyzed.

D. Select Tier 1 or Tier 2 analysis.

E. Specify desired accuracy of results.

F. Develop estimated budget for performance analysis.

G. Identify period of analysis.

$\mathrm{H}$. Gather basic site and PV system data.

I. Obtain pre-existing performance data.

\section{Measurement System Design (Section 6.3)}

A. Select performance metrics to be measured.

B. Identify data required for each metric.

C. Specify physical location of each measurement.

D. Specify frequency of each measurement.

E. Specify measurement equipment.

F. Determine feasibility of measurements.

G. Estimate cost of DAS equipment and operation.

$\mathrm{H}$. Calculate uncertainty of measurements.

I. Resolve cost, uncertainty, and practicality with expectations (Steps I.E and I.F).

III. Data Collection and Analysis (Section 6.4)

A. Validate data for quality control.

B. Assemble data for the period of analysis.

C. Calculate monthly metrics.

D. Calculate annual metrics.

\section{Reporting Results}

(See reporting formats in Section 7) 


\section{2 - Project Definition}

The form given in Appendix A (Table A-1) serves to guide and document the Project Definition stage of the procedure. Steps I.A through I.I, as shown in Table 6-1, are identified in Table A-1. Explanations of these steps follow.

Step I.A: Identify project goals. Summarize the purpose for conducting the performance analysis. Some examples of project goals are to

- Understand how energy is used and produced at the site

- Compare the energy production in this building to that of other buildings

- Determine energy cost savings accruing from the PV system.

Step I.B: List specific performance questions to be answered. Some examples of study questions are

- How much energy is produced by the PV system?

- What portion of the energy use is generated on site?

- How well does the PV system reduce peak building demands?

Step I.C: Determine the boundaries of the site to be analyzed. See the definition of site in Section 3.2. It is most convenient if the site to be analyzed corresponds to the energy utility metering. However, this may or may not satisfy the project goals and the questions to be answered.

Step I.D: Select Tier 1 or Tier 2 analysis. This procedure is divided into two tiers to differentiate the resolution of the results and the amount of effort typically required to complete the procedure. Tier 1 (the simpler level of analysis) provides monthly and annual results for the system as a whole. Tier 1 results are based on utility meter readings, building and PV system drawings, a physical examination (walkthrough) of the building, and other forms of pre-existing data. Tier 2 (the more detailed level of analysis) yields time-series results, in addition to monthly and annual results, based on a DAS with submetering.

Completion of either tier requires collecting at least 1 year of data while the building is in use. For a Tier 1 analysis of an existing building, such data have typically already been recorded on utility bills, so the procedure may be completed in a matter of days (see exception discussed below). For a complete Tier 1 analysis of a new building, a 1-year waiting period will be necessary to collect the data. For a Tier 2 analysis, the data collection is part of the procedure, which will necessarily take at least 1 year to complete.

The three primary metrics determined in a Tier 1 analysis are:

- $\quad$ Net PV System Production

- $\quad$ Net Facility Electricity Use

- Total Facility Electricity Use.

- $\quad$ Equivalent Hours of Peak Rated PV Production

Of these, monthly totals of Net Facility Electricity Use will generally be available from utility meter readings. If there is no Net PV System Production, the Total Facility Electricity Use is the same as the Net Facility Electricity Use. However, if the Net PV System Production is not zero, measured monthly 
values of this metric are also necessary. ${ }^{2}$ If such data are not already on hand (perhaps metered within the on-site power system), such metering must be performed as part of this procedure, delaying the analysis for 1 year. All the metrics that are determined in a Tier 1 analysis are listed in Table A-2, which is discussed in Section 6.3.

Tier 2 metrics are itemized by end use and recorded as time-series data with a DAS for a period of 1 year. From the time-series data, monthly and annual totals are also determined. All the metrics that are determined in a Tier 2 analysis are listed in Table A-3, which is discussed in Section 6.3.

Step I.E: Specify desired accuracy of results. More precise measurements will require more expensive monitoring equipment. Refer to the project goals (Step I.A) and questions (Step I.B) to help put this into perspective.

Step I.F: Develop estimated budget for performance analysis. The budget may dictate the appropriate level of effort or the necessary level of effort may dictate the budget. A trade-off between the two may be considered. The budget should include:

- The Project Definition effort

- The DAS purchase, installation, and operation (data collection), if used

- The analysis and reporting effort.

Step I.G: Identify period of analysis. For a Tier 1 analysis, this might correspond to the most recent year of utility bill records. For a Tier 2 analysis, it might be based on the time required to design, install, and commission a DAS, and then to operate it for 1 year. In either case, select the year that is representative of the normal, occupied function of the facility. Multiple years of analysis may also be possible to evaluate long-term trends and to verify energy savings.

Step I.H: Gather basic site and PV system data. Specific information about the building and PV system, which should be gathered before the Measurement System Design phase begins, is detailed in Table A-1 in Appendix A.

Step I.I: Obtain pre-existing performance data. Collect these data from utility bills or other sources detailing PV production and net facility electricity use, or from previously measured PV AC power production data. When suitable data are available, Tier 1 metrics are measurable, as explained in Step I.D.

\section{3 - Measurement System Design}

The purpose of the measurement system design is to ensure that the set of data collected will correspond to the desired analysis and results. This should help to eliminate two of the most common problems in building analysis: (1) insufficient data to complete the desired analysis, and (2) extraneous data that are collected but never used.

Forms are provided for use as checklists in completing the first five steps of the measurement system design. Blank forms are provided in Tables A-2 and A-3, for Tier 1 and Tier 2 analyses, respectively. Steps II.A through II.E correspond to columns in these forms.

\footnotetext{
${ }^{2}$ Alternatively, monthly values of the Total Site Electricity Use would enable the analysis.
} 
Step II.A: Select performance metrics to be measured. Review the list of performance metrics defined in this procedure, which are listed in the Performance Metric column in Table A-1 and Table A-2, and ascertain which ones apply to the analysis at hand. Cross out any metrics corresponding to features that do not exist at the site and any metrics for which results are not desired. If any additional measurements, not defined in this document, are required by the goals of the analysis (Step I.A) and the questions to be answered (Step I.B), include these metrics as additional items in the Performance Metrics column, so that the Measurement System Design will include them.

Step II.B: Identify data required for each metric. For each item remaining in the checklist, note the data that is required to compute the metric. Consult the metric definitions in Section 4 for details. In addition, consider the concerns discussed in Section 6.4 (Energy Balances and Unmeasurable Metrics) at this stage. In some cases, necessary data for calculated metrics may consist of other metrics in the checklist.

Step II.C: Specify physical location of measurement. For each necessary data stream, note the physical location at the site where these data will be measured. In addition to utility meter information, building drawings and specifications, walk-through inspections, and interviews with the building engineer and building occupants, data are typically collected using measurement equipment at strategic points within the PV and the building electrical systems. Figure 4-1 and Table 4-1 in Section 4 provide typical measurement locations of some of the metrics. Document the measurement locations in the PV system interconnection wiring schematic, as shown in Figure 7-1 in Section 7.

Step II.D: Specify frequency of each measurement. For each required measurement, note the measurement frequency. As described in Section 4, a Tier 1 analysis requires monthly data, while a Tier 2 analysis requires time-series data (see definition).

Step II.E: Specify measurement equipment. For each required measurement, list the measurement device(s) to be used. (See Appendix B for guidance on equipment selection.)

\section{Additional Steps in the Measurement System Design}

Step II.F: Determine feasibility of measurements. Having outlined any measurement devices to be used and the locations where they will be installed in the steps above, verify that this plan is practical. Project goals, tier levels, accuracy requirements, or expected performance metrics may have to be redefined based on the practicality of measurements. Two important tasks are to

- Verify configurations. Inspect the building wiring and any other features identified as Points of Measurement in the form, to verify that the physical configuration matches the drawings or assumptions on which the plan is based and that it enables the planned measurements. Examples of features to check include circuit breaker configuration, access to wiring for measurement purposes, and clearances for installing measurement devices. To monitor meters 3 and 4 in Figure 4.1, coordination with the electric utility may be required.

- Verify code conformity. Review the measurement system design with the local building department or another authority that has jurisdiction, to verify that the planned location of measurement devices will not violate code restrictions. If necessary, obtain an exception to the code before installing the measurement equipment. 
Step II.G: Estimate cost of DAS equipment and operation. If any new measurements are needed, include the following items when estimating the cost of implementing the measurement plan:

- The Measurement Equipment listed in Step II.E

- A data logger or other means of recording all of the required measurements, with applicable battery backup

- Data logger communications

- Installation and commissioning of the above equipment, including data logging programming

- The data collection effort: In addition to designing and installing DAS hardware that is capable of collecting the required data, it is also necessary to assign technical staff to operate the DAS. Experience has shown that hardware failures do occur, and these can result in a significant loss of data if problems are not promptly detected and remedied. At this stage, then, answer the following questions:

- Who will be responsible for data collection and quality control?

- How many hours per week will the responsible party(s) spend on this task?

- How will the data be collected and reviewed?

- How often will the data be checked?

- Data analysis and reporting

Weekly review is the recommended minimum frequency, but daily review is better, especially during the DAS installation and commissioning. Software that checks the data continuously and sends fault alarms to the technical staff is recommended, along with a telephone modem or network connection for remote monitoring.

Step II.H: Calculate uncertainty of measurements. Document the precision of each measurement device, and apply common statistical methods to calculate the uncertainty of metrics obtained through adding, subtracting, multiplying, and dividing measured data. The accuracy requirements determined in Step I must be balanced against measurement and analysis costs. See ASHRAE Guideline 14 (ASHRAE 2002) and the International Performance Measurement and Verification Protocol (IPMVP 2002) for applicable methods. See Appendix C for details on general uncertainty theory.

Step II.I: Resolve cost and uncertainty with expectations. Before purchasing any DAS equipment, compare the estimated cost (Step II.G) and measurement uncertainty (Step II.H) to the expectations that were set in the Project Definition phase (Steps I.E and I.F). Resolve any disparity by modifying either the estimated budget, the expected accuracy, or the design of the measurement system.

\section{4 - Data Collection and Analysis}

The task of data collection, if needed, consists of purchasing, installing, commissioning, and operating the DAS specified in the Measurement System Design phase, and monitoring the data for quality control. The quality control guidelines are described in Step II.G. Some analysis (for example, determining the monthly values of all the applicable metrics) should be conducted concurrently with data collection, to verify that the data set is complete and yields credible results.

The data analysis task consists of determining values of all applicable metrics based on the collected data. Some recommended practices follow. 
- Energy Balances. In cases where one metric is the sum of (or difference between) several other metrics, the recommended practice is to measure each metric individually and use the summation as a check on the consistency of the data. This is also a more accurate way to determine a total, rather than summing the constituent metrics. Any inconsistencies should be reconciled (corrected, or at least understood and reported).

- Unmeasurable Metrics. If a metric cannot practically be measured directly, it may need to be determined based on a sum of or difference between other metrics. However, this practice sacrifices the benefit of energy balance checking, and is less accurate.

- Missing Data. If intervals of data are missing because of a DAS malfunction, one of the following approaches should be applied:

- Extend the period of data collection so that a complete year of data is obtained, and modify the period of analysis to use the complete year of data.

○ Report "Missing Data" in lieu of metrics for the periods affected.

- Apply the best available method for estimating the missing data, and include the uncertainty introduced by this method in the reported measurement uncertainty. (Large, continuous gaps are more difficult than intermittent lapses to restore.)

In any case, maintain a log of all missing data and the method(s) used to reconcile the missing data.

\subsection{1 - Monthly Analysis}

The following procedures should be used to account for months that may vary in length, and for various utility billing periods.

\section{Identify Analysis Months}

Standard months are January through December, corresponding to the Gregorian calendar.

Nonstandard months may be any 12 approximately equal divisions of a year. For example, nonstandard months may correspond to a utility billing cycle, provided it consists of 12 consecutive, approximately equal intervals that cover approximately 365 days. They may be named January, February, and so on, according to the standard month in which most of the days occur. Alternatively, they may be named Month 1, Month 2, etc., or another convenient designation.

For a Tier 1 analysis, in which the primary source of energy use data is utility bills, the analysis months should be chosen to correspond to the utility billing cycle. If more than one utility is used, and they are on different billing cycles, the one with the highest annual use should be favored. This approach minimizes errors caused by estimating the portion of the utility use that occurs within the analysis month (see Accommodate Nonsynchronous Utility Billing Periods, below).

\section{Use Average Daily Values}

Monthly metrics should be reported as monthly totals in tabular form and as average daily values in graphical form. The use of average daily values prevents the weighting of metrics by the number of days per month, which may vary slightly from one month to another. 


\section{Identify the Analysis Year}

Annual totals are determined by summing 12 consecutive monthly totals and adjusting for the number of included days. An analysis year consists of 365 consecutive days, whether or not the data were collected during a leap year. ${ }^{3}$ In the event that the 12 consecutive months amount to slightly more or fewer than 365 days, the total should be adjusted by adding or subtracting average daily values symmetrically at the beginning and end of the analysis year.

\section{Examples:}

1. Standard months in a leap year.

A sum of energy totals for January through December includes 366 days. This sum is adjusted to 365 days by subtracting one half of the average daily value for January and one half of the average daily value for December.

2. Utility billing periods that cover fewer than 365 days.

The utility bill analysis year runs from April 3 through March 29. The variations in the meter reading dates cause these 12 consecutive months cover only 361 days. Thus, the annual total is adjusted to 365 days by adding 2 times the average daily value for "April" and 2 times the average daily value for "March."

\section{Accommodate Nonsynchronous Utility Billing Periods}

If one or more utilities (e.g., electricity and natural gas) are billed on schedule(s) that do not correspond to the analysis months, the following procedure should be used to determine monthly metrics that involve the utilities in a Tier 1 analysis.

For each day in the analysis month, for each utility, the average daily value of the utility use for the billing period that includes the day in question applies. These values are totaled for each utility, for each day in the analysis month, to determine the monthly total. Finally, the monthly totals are divided by the numbers of days in the analysis months to determine the average daily values.

\section{Example:}

Standard months are used for January 1 to December 31, 2005 (not a leap year). Electricity is billed on the 10th of each month. Natural gas is billed on the 20th of each month.

- For January 1, 2005 through January 10, 2005, the daily electricity use is the average daily value for the billing period December 10, 2004 to January 10, 2005. The gas use is the average daily value for the billing period December 20, 2004 to January 20, 2005.

- For January 11, 2005 through January 20, 2005, the daily electricity use is the average daily value for the billing period January 10, 2005 to February 10, 2005. The gas use is the average daily value for the billing period December 20, 2004 to January 20, 2005.

- For January 21, 2005 through January 31, 2005, the daily electricity use is the average daily value for the billing period January 10, 2005 to February 10, 2005. The gas use is the average daily value for the billing period January 20, 2005 to February 20, 2005.

\footnotetext{
${ }^{3}$ This is to avoid a slight bias in annual metrics measured in leap years versus nonleap years.
} 
The January totals are determined by summing the daily values from January 1, 2005 through January 31, 2005. Then the average daily values are determined by dividing the January totals by 31 days.

\section{Section 7 - Reporting Format}

To facilitate comparisons among various projects, this section gives a set of standard formats for reporting on the results of this procedure in a consistent manner. The final report for this procedure should include the items outlined in the sections that follow.

\section{1 - Tier 1}

- Project Definition form (see Table A-1)

- Table of Monthly Metrics, including all applicable metrics listed in the Measurement Plan (Table A-2) and using the reporting format illustrated in Table 7-1.

\section{2 - Tier 2}

- Project Definition form (see Table A-1)

- Diagram of measurement scheme, showing locations of measurements, similar to the example in Figure 7-1

- Table of Monthly Metrics, including all applicable metrics listed in the Measurement Plan (Table A-3), using the reporting format illustrated in Table 7-1. An example of a production profile, a generation effectiveness versus insolation plot, and a daily performance ratio plot are shown in Figures 7-2, 7-3, and 7-4. 
Table 7-1 Example PV Performance Summary, March 1, 2001, through February 28, 2002

\begin{tabular}{|c|c|c|c|c|c|c|c|c|c|c|c|c|c|}
\hline \multirow[t]{2}{*}{ Metric } & \multicolumn{12}{|c|}{ Month } & \multirow[t]{2}{*}{ Annual } \\
\hline & 1 & 2 & 3 & 4 & 5 & 6 & 7 & 8 & 9 & 10 & 11 & 12 & \\
\hline Net PV Production & & & & & & & & & & & & & \\
\hline $\begin{array}{l}\text { Total Facility } \\
\text { Energy Use }\end{array}$ & & & & & & & & & & & & & \\
\hline $\begin{array}{l}\text { Facility Electrical } \\
\text { Load Offset by PV } \\
\text { Production }\end{array}$ & & & & & & & & & & & & & \\
\hline $\begin{array}{l}\text { PV System AC } \\
\text { Electricity } \\
\text { Generation } \\
\text { Effectiveness }\end{array}$ & & & & & & & & & & & & & \\
\hline $\begin{array}{l}\text { Net Facility } \\
\text { Electricity use }\end{array}$ & & & & & & & & & & & & & \\
\hline $\begin{array}{l}\text { Peak Demand of } \\
\text { Net Facility } \\
\text { Electricity Use }\end{array}$ & & & & & & & & & & & & & \\
\hline $\begin{array}{l}\text { Peak Demand of } \\
\text { Total Facility } \\
\text { Electricity Use } \\
\text { without PV System }\end{array}$ & & & & & & & & & & & & & \\
\hline $\begin{array}{l}\text { Reduction of Peak } \\
\text { Demand Resulting } \\
\text { from PV System }\end{array}$ & & & & & & & & & & & & & \\
\hline $\begin{array}{l}\text { Energy Cost } \\
\text { Savings Resulting } \\
\text { from PV System }\end{array}$ & & & & & & & & & & & & & \\
\hline
\end{tabular}

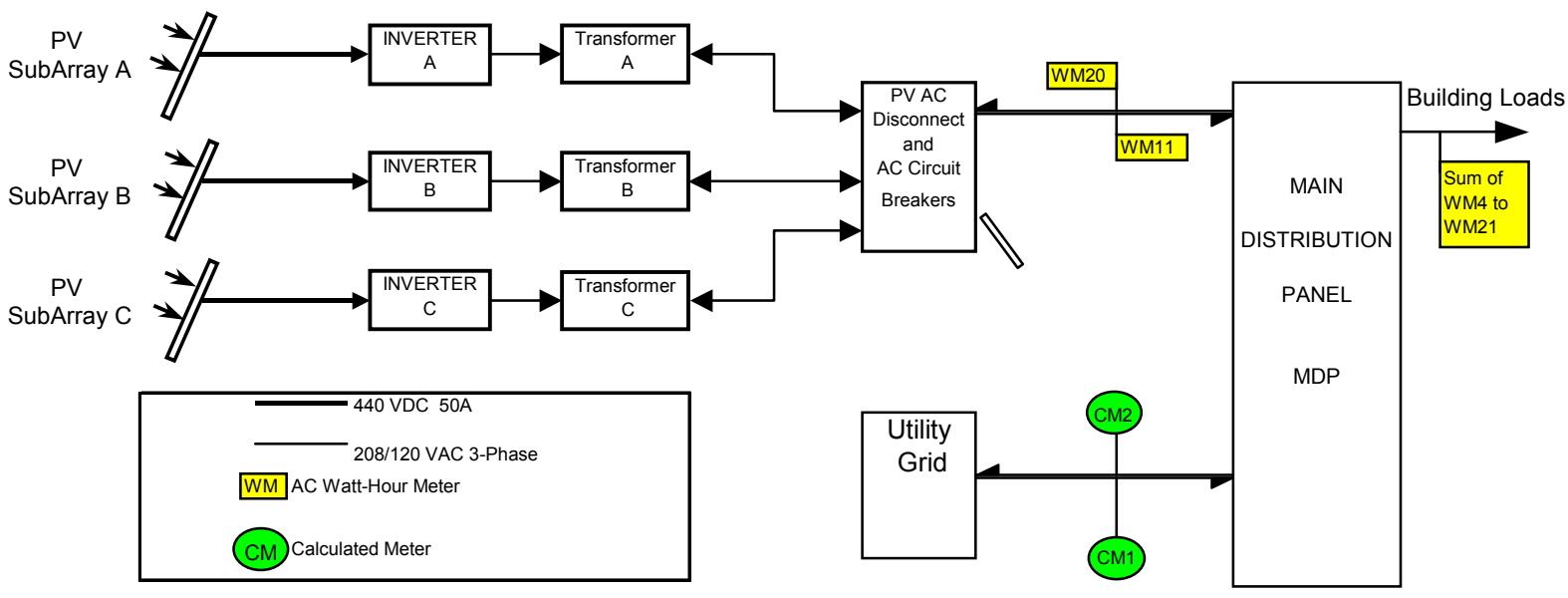

Figure 7-1 Example PV system interconnection wiring and metering schematic 


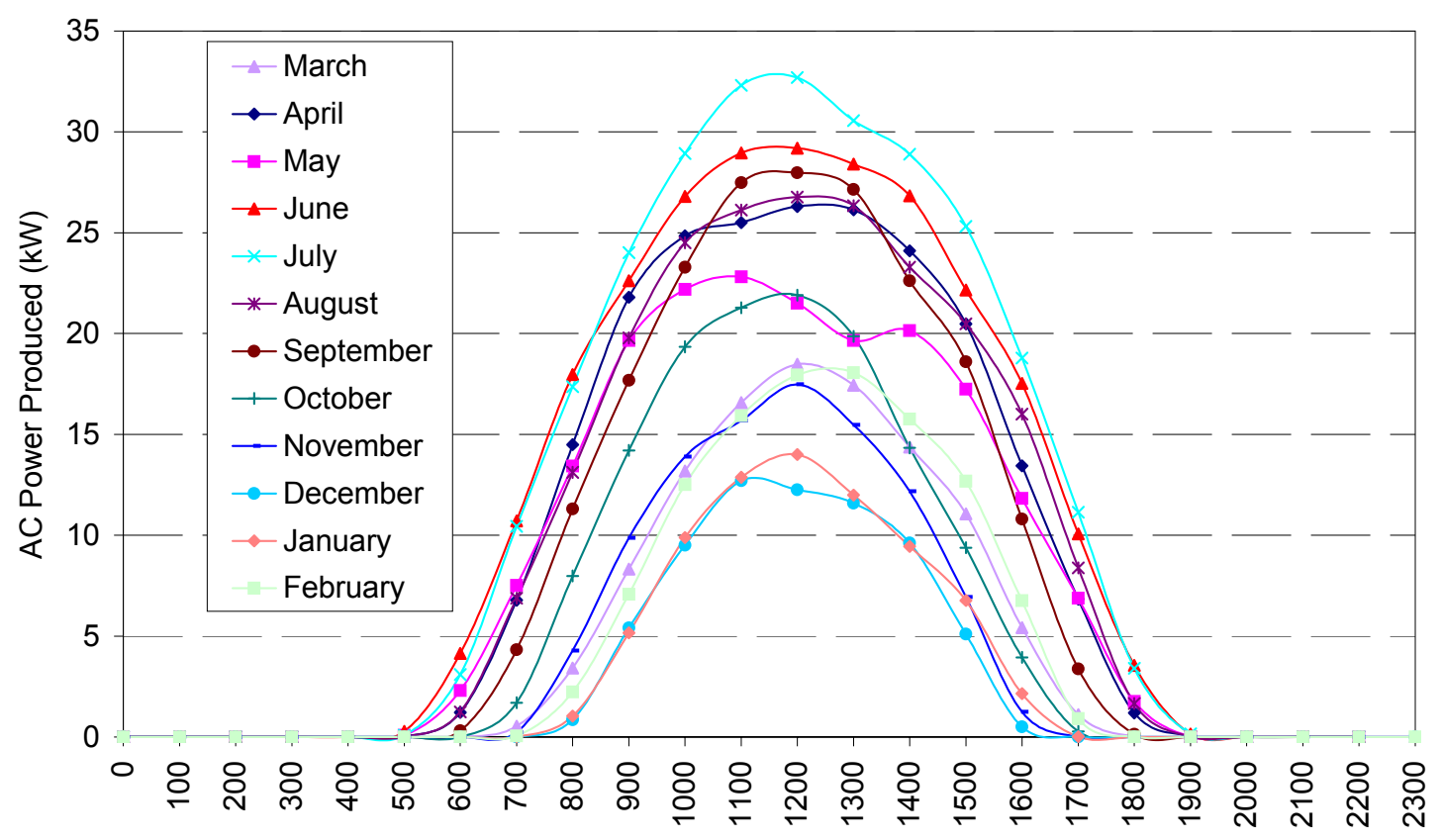

Hour of the Day

Figure 7-2 Total PV production shape profiles

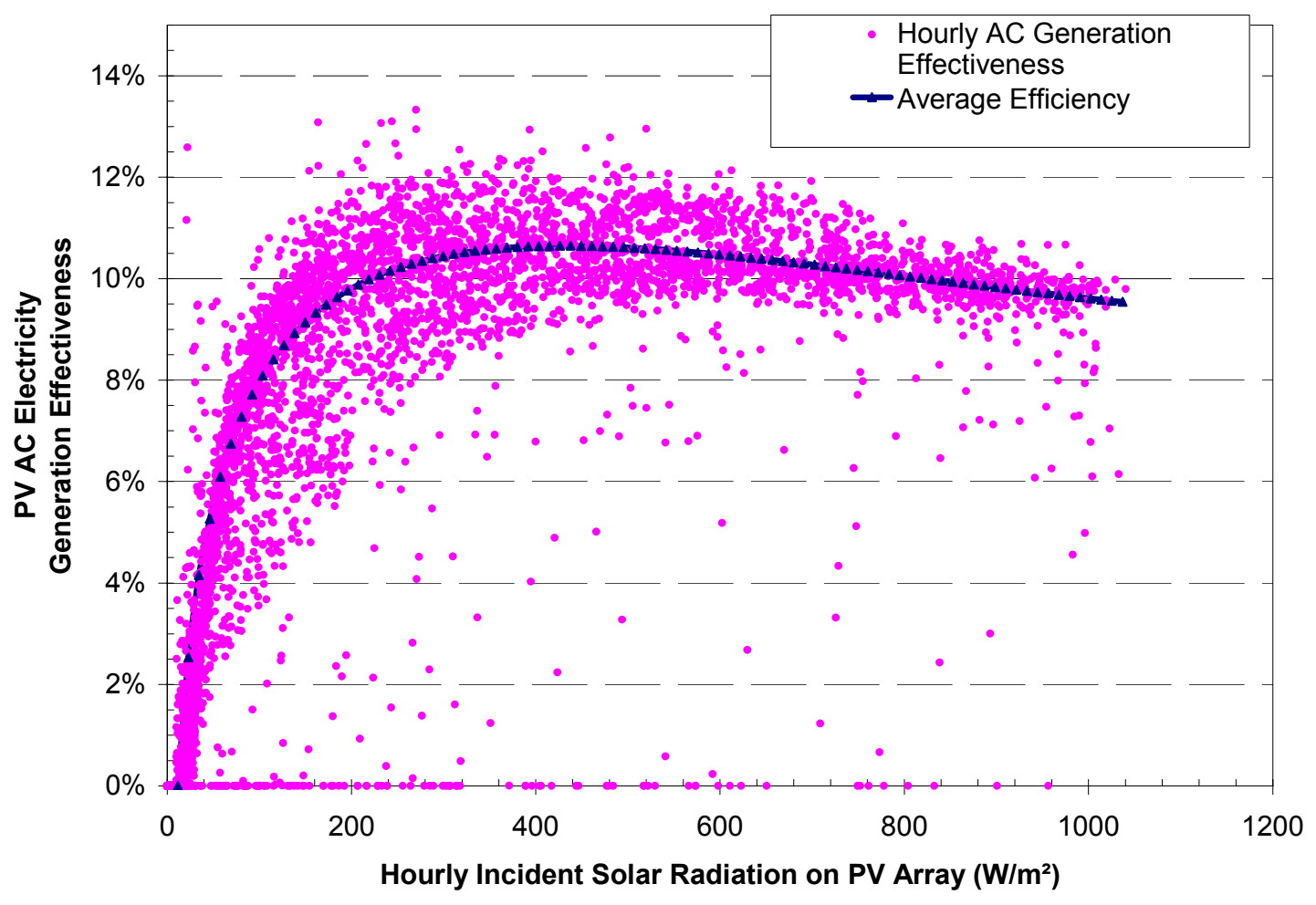

Figure 7-3 AC generation efficiencies versus incident solar radiation 


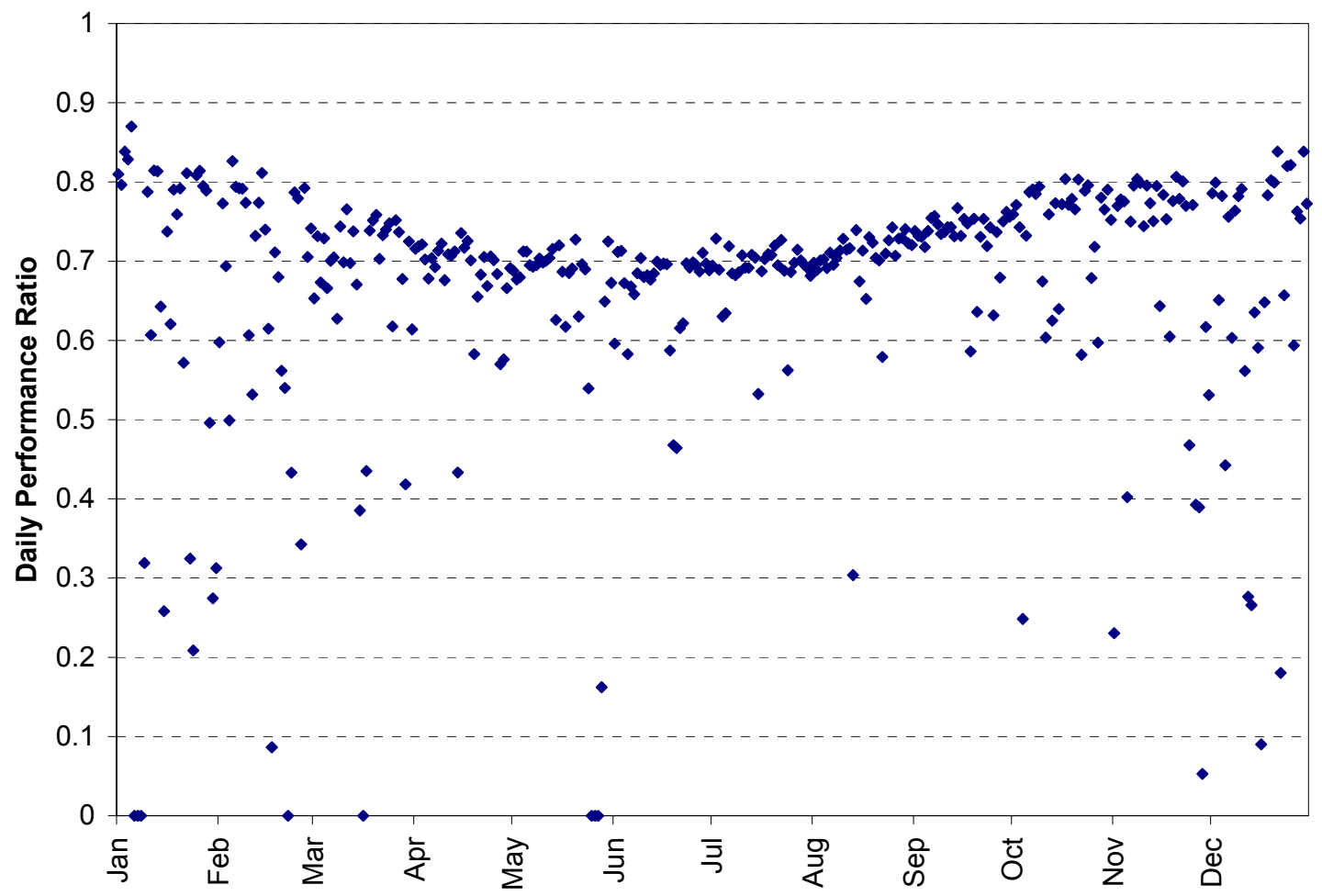

Figure 7-4 Daily performance ratio

\section{3 - Reporting Cost Metrics}

When energy costs are compared between two buildings that have been analyzed at different times or in different places, several factors may bias the comparison:

- Changes in energy prices over time

- Differences in energy prices from place to place

- General inflation that occurs during the time interval

- Exchange rates between different currency units, which vary over time.

It is beyond the scope of this procedure to develop a system for normalizing all these effects. However, the following procedures should be used to report cost metrics in a way that will facilitate their interpretation.

The following metrics defined in this procedure include units of currency:

- Facility Electricity Costs, Currency Year

- Facility Electricity Costs without PV System, Currency Year $_{\text {P }}$

- Energy Cost Savings Resulting from PV System, Currency $\mathrm{Y}_{\mathrm{Year}} / \mathrm{ft}^{2}$ or Currency $\mathrm{y}_{\text {Year }} / \mathrm{m}^{2}$ 
In each case where currency units are used, the year during which the expenditures occurred should be noted. If the analysis year extends over two calendar years, the calendar year during which most of the expenditures occurred should be cited.

\section{Example:}

- $\quad$ Facility Electricity Cost (Annual) $=\mathrm{US}_{2001} 6,500 / \mathrm{yr}$

In addition, footnotes should be used to reference the building location and the applicable utility rate schedule(s). These are documented in the Project Definition Form (Table A-1).

\section{Section 8 - References}

ASHRAE (2005). ASHRAE Handbook of Fundamentals. Atlanta, GA: American Society of Heating, Refrigerating and Air-Conditioning Engineers, Inc.

ASHRAE (2002). Measurement of Energy and Demand Savings. ASHRAE Guideline 14-2002. Atlanta, GA: American Society of Heating, Refrigerating and Air-Conditioning Engineers, Inc.

ASTM E 1036-96 (1996). Standard Test Methods for Electrical Performance of Nonconcentrator Terrestrial Photovoltaic Modules and Arrays Using Reference Cells. West Conshohocken, PA: American Society for Testing and Materials.

Barley, C.D.; Deru, M.; Pless, S.; Torcellini, P.; (2005). Procedure for Measuring and Reporting Commercial Building Energy Performance. Technical Report NREL/TP-550-38601. Golden, CO: National Renewable Energy Lab (http://www.nrel.gov/publications/).

Haberl, J.; Lopez, R.; and Sparks, R. (1992). LoanSTAR Monitoring and Analysis Program: Building Energy Monitoring Workbook. Energy Systems Laboratory Report No. ESL-TR-92/06-03, College Station, TX: Texas A\&M University.

Haberl, J.; Reddy, T.; Claridge, D.; Turner, D.; O'Neal, D.; and Heffington, W. (1996). Measuring Energy-savings Retrofits: Experiences from the Texas LoanSTAR Program, Energy Systems Laboratory, Texas A\&M University. ORNL/Sub/93-SP090/1, Oak Ridge, TN: Oak Ridge National Laboratory.

IEC 61724 (1998). "International Standard 61724: Photovoltaic system performance monitoringGuidelines for measurement, data exchange, and analysis." International Electotechnical Commission, Geneva, Switzerland.

IPMVP. (2002). Concepts and Options for Determining Energy and Water Savings. Volume I. Available at www.ipmvp.org. (Accessed April 18, 2003.)

Marion, B.; Kroposki, B.; Emery, K.; del Cueto, J.; Myers, D.; Osterwald, C. (1999). Validation of a Photovoltaic Module Energy Ratings Procedure at NREL. NREL/TP-520-26909, Golden, CO: National Renewable Energy Laboratory, 1999.

Misuriello, H.P. (1987). "A Uniform Procedure for the Development and Dissemination of Monitoring Protocols." ASHRAE Transactions 93(1). Atlanta, GA: American Society of Heating, Refrigerating and Air-Conditioning Engineers, Inc. 
NEC (2002). National Electric Code, Article 690.2. Quincy, MA: National Fire Protection Association, Inc.

PG\&E Co. (1995). R.N. Dows, "PVUSA Procurement, Acceptance, and Rating Practices for Photovoltaic Power Plants.” PG\&E Co. Report \#95-30910000. Sept. 1995.

Stewart, R.; Stewart, S.; Joy, R. (1984). "Energy Audit Input Procedures and Forms.” ASHRAE Transactions 90(1A):350-62. Atlanta, GA: American Society of Heating, Refrigerating and AirConditioning Engineers, Inc. 


\section{Appendix A - Sample Measurement Plan}

\section{Table A-1 Project Definition Form}

Project Name:

Building Address:

All Site/Procedure Related Contacts:

(Names, organization, title, contact info)

(I.A) Goals of the Analysis:

(I.B) Questions to be Answered:

(I.C) Site Definition and Boundaries:

(I.D) Analysis Tier (Tier 1 or Tier 2):

(I.E) Desired Accuracy of Results:

$\pm \quad \%$, or other criteria

(I.F) Estimated Budget for Performance Analysis:

(I.G) Dates of:

Procedure execution:

Site visits:

Monitoring period:

(I.H) Basic Building and PV System Data:

Building Description:

(Floor plan, gross area, floors, space uses, typical occupancy patterns)

PV System Description:

- $\quad$ Rated PV module capacity

- $\quad$ Array area

- $\quad$ Array wiring schematic

- $\quad$ BOS components and system wiring

- $\quad P V$ interconnection wiring schematic showing the building and utility connection.

Utility Company(s) and Rate Schedule(s):

(Attach to this form)

Pre-existing Performance Data:

Principal Building Function:

The principal building type is classified according to the principal commercial activity, which is the primary business, commerce, or function carried on within each building (EIA 2002). Choose One:

$\square$

\begin{tabular}{l|l|l} 
Education & & Health Care \\
$\begin{array}{l}\text { Food Sales } \\
\text { Sood }\end{array}$ & & Lodging \\
& & Mervice
\end{tabular}
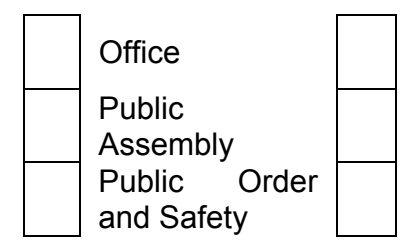

Religious Worship

Other Service

Warehouse and Storage

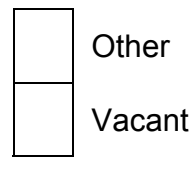


Table A-2 Tier 1 Metrics Measurement Plan

\begin{tabular}{|l|l|l|l|}
\hline \multicolumn{1}{|c|}{ Tier 1 Metrics } & \multicolumn{1}{|c|}{$\begin{array}{c}\text { Data Needed } \\
\text { (in bold if data represent another } \\
\text { metric) }\end{array}$} & $\begin{array}{l}\text { Measurement } \\
\text { Location or } \\
\text { Source of Data }\end{array}$ & $\begin{array}{c}\text { Frequency of } \\
\text { Measurement }\end{array}$ \\
\hline $\begin{array}{l}\text { Total PV System } \\
\text { Production }\end{array}$ & $\begin{array}{l}\text { Monthly utility bills or monthly pre- } \\
\text { existing performance data }\end{array}$ & & \\
\hline PV System Standby Use & \multicolumn{1}{|c|}{} & \\
\hline $\begin{array}{l}\text { Net PV System } \\
\text { Production }\end{array}$ & $\begin{array}{l}\text { Total PV System Production and } \\
\text { Standby Use }\end{array}$ & & \\
\hline $\begin{array}{l}\text { Equivalent Daily Hours of } \\
\text { Peak Rated PV } \\
\text { Production }\end{array}$ & $\begin{array}{l}\text { Net PV System Production and } \\
\text { Rated PV capacity }\end{array}$ & \\
\hline $\begin{array}{l}\text { Equivalent Annual Hours } \\
\text { of Peak Rated PV } \\
\text { Production }\end{array}$ & $\begin{array}{l}\text { Net PV System Production and } \\
\text { Rated PV capacity }\end{array}$ & \\
\hline $\begin{array}{l}\text { Total Facility Electricity } \\
\text { Use }\end{array}$ & $\begin{array}{l}\text { Monthly utility bills or monthly pre- } \\
\text { existing performance data }\end{array}$ & \\
\hline $\begin{array}{l}\text { Total Facility Energy Use } \\
\text { Monthly utility bills or monthly pre- } \\
\text { existing performance data }\end{array}$ & & \\
\hline $\begin{array}{l}\text { Facility's Electrical Load } \\
\text { Offset by PV Production }\end{array}$ & $\begin{array}{l}\text { Net PV System Production and } \\
\text { Total Facility Electricity Use }\end{array}$ & & \\
\hline $\begin{array}{l}\text { Facility's Total Energy } \\
\text { Load Met by PV } \\
\text { Production }\end{array}$ & $\begin{array}{l}\text { Net PV System Production and } \\
\text { Total Facility Energy Use }\end{array}$ & & \\
\hline
\end{tabular}


Table A-3 Tier 2 Metric Measurement Plan

\begin{tabular}{|c|c|c|c|}
\hline Tier 2 Metrics & $\begin{array}{c}\text { Data Needed } \\
\text { (in bold if data represent another } \\
\text { metric) }\end{array}$ & $\begin{array}{l}\text { Measurement } \\
\text { Location or } \\
\text { Source of Data }\end{array}$ & $\begin{array}{l}\text { Frequency of } \\
\text { Measurement }\end{array}$ \\
\hline $\begin{array}{l}\text { Total PV System } \\
\text { Production }\end{array}$ & $\begin{array}{l}\text { Time-series measurement of AC PV } \\
\text { production }\end{array}$ & & \\
\hline PV System Standby Use & $\begin{array}{l}\text { Time-series measurement of PV } \\
\text { system standby use }\end{array}$ & & \\
\hline $\begin{array}{l}\text { Net PV System } \\
\text { Production }\end{array}$ & $\begin{array}{l}\text { Total PV System Production and } \\
\text { PV System Standby Use }\end{array}$ & & \\
\hline $\begin{array}{l}\text { Equivalent Daily Hours } \\
\text { of Peak Rated PV } \\
\text { Production }\end{array}$ & $\begin{array}{l}\text { Net PV System Production and } \\
\text { Rated PV capacity }\end{array}$ & & \\
\hline $\begin{array}{l}\text { Equivalent Annual } \\
\text { Hours of Peak Rated PV } \\
\text { Production }\end{array}$ & $\begin{array}{l}\text { Net PV System Production and } \\
\text { Rated PV capacity }\end{array}$ & & \\
\hline $\begin{array}{l}\text { Total Facility Electricity } \\
\text { Use }\end{array}$ & $\begin{array}{l}\text { Monthly utility bills or monthly pre- } \\
\text { existing performance data }\end{array}$ & & \\
\hline $\begin{array}{l}\text { Total Facility Energy } \\
\text { Use }\end{array}$ & $\begin{array}{l}\text { Monthly utility bills or monthly pre- } \\
\text { existing performance data }\end{array}$ & & \\
\hline $\begin{array}{l}\text { Facility's Electrical } \\
\text { Load Offset by PV } \\
\text { Production }\end{array}$ & $\begin{array}{l}\text { Net PV System Production and } \\
\text { Total Facility Electricity Use }\end{array}$ & & \\
\hline $\begin{array}{l}\text { Facility's Total Energy } \\
\text { Load Met by PV } \\
\text { Production }\end{array}$ & $\begin{array}{l}\text { Net PV System Production and } \\
\text { Total Facility Energy Use }\end{array}$ & & \\
\hline $\begin{array}{l}\text { Total Electricity } \\
\text { Delivered to Utility }\end{array}$ & $\begin{array}{l}\text { Time-series measurement of energy } \\
\text { exported to utility }\end{array}$ & & \\
\hline $\begin{array}{l}\text { Total Incident Solar } \\
\text { Radiation }\end{array}$ & $\begin{array}{l}\text { Time-series measurement of } \\
\text { insolation, array area }\end{array}$ & & \\
\hline $\begin{array}{l}\text { PV System AC } \\
\text { Electricity Generation } \\
\text { Effectiveness }\end{array}$ & $\begin{array}{l}\text { Total Incident Solar Radiation and } \\
\text { Net PV System Production }\end{array}$ & & \\
\hline $\begin{array}{l}\text { PV System Performance } \\
\text { Ratio }\end{array}$ & $\begin{array}{l}\text { PV System AC Electricity } \\
\text { Generation Effectiveness and rated } \\
\text { PV module efficiency }\end{array}$ & & \\
\hline $\begin{array}{l}\text { Net Facility Electricity } \\
\text { Use }\end{array}$ & $\begin{array}{l}\text { Time-series measurement of Total } \\
\text { Electricity Delivered to Utility and } \\
\text { Time-series measurement of energy } \\
\text { consumed from utility }\end{array}$ & & \\
\hline $\begin{array}{l}\text { Peak Demand of Net } \\
\text { Facility Electricity Use }\end{array}$ & $\begin{array}{l}\text { Time-series measurement of Net } \\
\text { Facility Electricity Use }\end{array}$ & & \\
\hline $\begin{array}{l}\text { Peak Demand of Total } \\
\text { Facility Electricity Use } \\
\text { without PV System }\end{array}$ & $\begin{array}{l}\text { Time-series measurement of Total } \\
\text { Facility Energy Use }\end{array}$ & & \\
\hline $\begin{array}{l}\text { Reduction of Peak } \\
\text { Demand Resulting from } \\
\text { the PV system }\end{array}$ & $\begin{array}{l}\text { Peak Demand of Net Facility } \\
\text { Electricity Use and Peak Demand } \\
\text { of Total Facility Electricity Use } \\
\text { without PV System }\end{array}$ & & \\
\hline Facility Electricity Costs & Utility bills & & \\
\hline
\end{tabular}




\begin{tabular}{|l|l|l|l|}
\hline \multicolumn{1}{|c|}{ Tier 2 Metrics } & \multicolumn{1}{|c|}{$\begin{array}{c}\text { Data Needed } \\
\text { (in bold if data represent another } \\
\text { metric) }\end{array}$} & $\begin{array}{l}\text { Measurement } \\
\text { Location or } \\
\text { Source of Data }\end{array}$ & $\begin{array}{l}\text { Frequency of } \\
\text { Measurement }\end{array}$ \\
\hline $\begin{array}{l}\text { Facility Electricity Costs } \\
\text { without PV System }\end{array}$ & $\begin{array}{l}\text { Time-series measurement of Total } \\
\text { Facility Electricity Use and Utility rate } \\
\text { structure }\end{array}$ & & \\
\hline $\begin{array}{l}\text { Energy Cost Savings } \\
\text { Resulting from PV } \\
\text { System }\end{array}$ & $\begin{array}{l}\text { Facility Electricity Costs without } \\
\text { PV System and Facility Electricity } \\
\text { Costs }\end{array}$ & & \\
\hline $\begin{array}{l}\text { Maximum Time-Series } \\
\text { Net PV Production }\end{array}$ & $\begin{array}{l}\text { Time-series measurement of Net PV } \\
\text { System Production }\end{array}$ & & \\
\hline $\begin{array}{l}\text { Average Daily Time- } \\
\text { Series PV Production } \\
\text { Profiles }\end{array}$ & $\begin{array}{l}\text { Time-series measurement of Net PV } \\
\text { System Production }\end{array}$ & & \\
\hline
\end{tabular}




\section{Appendix B - Description of Monitoring Equipment}

This appendix contains a brief introduction to measurement techniques and equipment - it is not meant to be a definitive source of information. The reader is encouraged to conduct further research into these techniques and equipment if there are additional questions after reading this section. For additional information on building energy monitoring equipment and methods, see the ASHRAE Handbook of Fundamentals (2005), ASHRAE Guideline 14 (2002), and International Performance Measurement and Verification Protocol, Volume I (2002).

Maintain the calibration of all instruments according to the manufacturers' recommendations. Some instruments must be field calibrated after installation. Instruments may require recalibration or replacement during long monitoring periods. Maintain a record of all instrument calibrations during the monitoring period.

\section{B.1 - Data Logger}

The data logger is the most important piece of equipment in the data acquisition system (DAS). The options are usually to use small, self-contained units that house the sensors and data logger, or to use one or more central data loggers. Although the self-contained units are easy to install, they do not allow remote access to the data, they must be synchronized with other units, and they generate multiple data files. A central data logger can be expensive; however, it will usually pay for itself in saved time during data collection and analysis. Some building automation systems (BAS) can log and store data, but their use as data loggers should be analyzed carefully. Most BAS are not designed to be data loggers; therefore, problems with precision, scan rate, storage, retrieval, or reliability may arise. The following features are key in a central data logger:

- Reliability: The data logger must be dependable and robust. If the data logger fails, all the data will be lost for that period; the data collected up to the point of failure may be lost as well. A reliable data logger usually pays for itself by reducing maintenance costs and avoiding lost data.

- Memory: The data logger must be able to store the collected data for long periods in case there are times when the data cannot be retrieved. Recording time-series data can create large data files. Ideally, a data logger should be able to store many months of data without running out of memory.

- Communications: Most data loggers have, at a minimum, an RS232 port for direct connection to a computer. For long-term data monitoring, remote communication capabilities that allow data retrieval, data logger programming, and data logger troubleshooting are usually preferable. For building applications, remote access is usually through a telephone modem, a cell phone modem, or an Internet connection.

- Data Storage Format: The format of the data storage should be straightforward and easy to work with. Some systems have storage formats that are difficult to process and may even result in lost data. The easiest format is usually a comma-delimited text file with a date and time stamp for each set of readings.

- Versatility: A good data logger will be flexible enough to handle many types of sensors and ranges of inputs. Sensor outputs may be voltage, current, or pulses. The data logger should also be able to supply excitation outputs to power sensors. Its scan rate should be an order of magnitude greater than the dynamics of the system being monitored. The data logger should also be able to expand to handle many inputs. 
- Programmability: Many data loggers include built-in functions for converting signals from sensors into convenient engineering units. Examples include simple mathematical expressions, complex thermocouple (TC) conversions, and combining flow and temperatures to calculate energy flow (e.g. "Btu meter"). Programming the data logger to perform these tasks reduces the amount of data postprocessing and facilitates quick data assessments.

- Capability for Backup Power: The data logger should be able to operate for at least 2-4 weeks on backup power in case of a power outage or if it is inadvertently unplugged.

\section{B.2 - Alternating Current Power Measurements}

In alternating current $(\mathrm{AC})$ systems, the voltage and current waveforms vary with time over a cycle. Thus, the power is also cyclic, and the desired measurement is the average power over a cycle. The type of equipment needed to measure $\mathrm{AC}$ power depends on the current waveform, i.e., whether it is a sine wave and whether it is in phase with the voltage waveform. A power transducer is a device that can accurately measure the average power in any situation, regardless of the type of current waveform. However, in some cases a simpler method is recommended. Generally there are three cases to consider, depending on the type of load.

1. Case 1: Resistive loads. In loads that behave as resistors (with $\mathrm{E}=\mathrm{I} \cdot \mathrm{R}$ ), such as incandescent lights and electrical resistance heaters (water heater, duct heater, electric baseboard, etc.), the current is a sinusoid in phase with the voltage. In this case, the recommended measurement scheme is to monitor the RMS ${ }^{4}$ voltage and RMS current, and compute the power as

$$
\text { Power }=(\text { RMS voltage }) \times(\text { RMS current }) .
$$

2. Case 2: Sinusoid out of phase. If the current is a sinusoid that is out of phase with the voltage, such as electric motors (blower, pump, compressor, etc.), the formula for the power is: ${ }^{5}$

Power $=($ RMS voltage $) \times($ RMS current $) \times($ power factor $)$.

If the power factor were a constant, it would be sufficient to measure the power factor once, monitor the RMS voltage and RMS current, and use this formula. However, any changes in the loading of a motor, such as dirt buildup on an air filter, corrosion of pipes, or changes in heat pump operating temperatures, can cause the power factor to vary. Therefore, the recommended measurement scheme is to use a power transducer.

3. Case 3: Nonsinusoidal current. If the current is an irregular (nonsinusoidal) waveform, such as fluorescent lights, dimmer controls, or other loads, a power transducer must be used.

$\mathrm{AC}$ current can be measured by a split core CT that fits around an existing wire without interrupting it (the wire does not need to be cut to install the device). When a power transducer is used, a similar type of $\mathrm{CT}$ is attached to the power transducer, along with a voltage connection. If electrical energy flows in both directions in the same wire, two sets of unidirectional CTs and watt-hour transducers, or one bidirectional device, may be required. The CTs should be sized for maximum expected load and not the breaker size. Breakers usually have a higher rating than the maximum load on the circuit. Oversized CTs will lower the accuracy of the measurements. Many CTs have a linear range of response between $10 \%$ and $130 \%$ of their rated capacity.

$\mathrm{AC}$ voltage should be monitored continuously with an $\mathrm{AC}$ voltage transducer if it is required for power calculations. Even though the grid voltage has a fixed nominal value, the actual voltage varies

\footnotetext{
${ }^{4} \mathrm{RMS}$ is the square root of the average value of the square of the quantity. This is a special type of average that applies in power calculations. Devices are available that measure RMS voltage and RMS current.

${ }^{5}$ The power factor is the cosine of the phase angle between the voltage and current waveforms, when both waveforms are sinusoids.
} 
significantly with changing load conditions. A typical bus voltage variation is $\pm 5 \%$. The electric utility company may quote a more specific tolerance.

\section{Three-Phase Power Systems}

If three-phase electrical power needs to me measured, it will require three-phase power transducers. The power transducer should be selected based on the wiring configuration (three-phase/three-wire or threephase/four-wire). Various three-phase power transducer models feature watt, volt-ampere, power factor, and watt-hour outputs; various response times; and the ability to accommodate chopped or distorted voltage and current waveforms within the accuracy specifications.

\section{B.3 - Direct Current Power Measurements}

CTs, and thus the type of power transducer that is recommended for AC power measurements (Section B.2), do not work with direct current (DC). Two general classes of alternative methods are available:

- Electrically coupled. The DAS shares a common electrical ground with the system being monitored. Measurement apparatus is relatively inexpensive.

- Electrically isolated. The DAS is electrically isolated from the system being monitored. Measurement apparatus is more expensive. This requirement may occur, for example, in a gridconnected photovoltaic (PV) system, where the design of the inverter requires that the DC power circuitry be isolated from ground.

When DC voltage and current are measured separately, the instantaneous DC power is the product of the current times the voltage. Often, the DC power will have some periodic components or other fluctuations in it because of the pulsating nature of current or voltage waveforms in DC systems introduced by rectifiers, inverters, and so on. In such cases, the sampling rate must be high enough to capture and analyze the fluctuations, and the average DC power can be calculated for any desired averaging period.

\section{Electrically Coupled Systems}

A voltage divider is recommended to measure DC voltage in electrically coupled systems. This consists of a simple network of two precision resistors in series, which reduces the range of voltages in the system to the range of voltages accepted by the DAS. The corresponding conversion factor is used to interpret the measurements for data analysis.

A shunt resistor is recommended to measure DC current in electrically coupled systems. A precision lowresistance resistor is placed in series with the circuit to be monitored. The resistance value is chosen to convert the range of currents in the system to the range of voltages accepted by the DAS. The power rating of resistor must also be chosen to accommodate the amount of power consumed (and thus heat generated) in the shunt resistor.

\section{Electrically Isolated Systems}

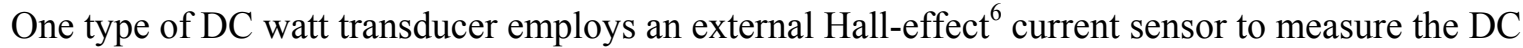
power. In some cases, for low current systems (up to $20 \mathrm{~A}$ ) there is no need for an external current sensor because the watt transducer comes with its own internal current sensors. Hall-effect current sensors are more complex and expensive than simple current shunts. However, the Hall-effect technology is a noncontact method of current measurement that provides electrical isolation. For the same reason, electrically isolated voltage transducers are much safer to use than inexpensive voltage dividers. The lack of electrical isolation may damage the DAS in case of overvoltage events, lightning strikes, and other mishaps.

Among other benefits, the Hall-effect current sensors come in a split-core configuration. This allows the power measurement equipment to be installed in just a few minutes without breaking the existing power

\footnotetext{
${ }^{6}$ Hall-effect current measurement is a noncontact technique that measures the magnetizing effects of current flowing in a conductor.
} 
lines. In field applications, problems have been experienced with maintaining the calibration of Halleffect sensors. One problem is the temperature sensitivity of the calibration.

Another option is to use DC voltage and current transducers that achieve electrical isolation without the use of the Hall effect. Some are unidirectional and some are bidirectional. Typical accuracies are $\pm 0.25 \%-1 \%$ of full scale plus $0.25 \%$ of reading. As of this writing, prices are about $\$ 200-\$ 400$ per sensor.

\section{B.4 - Solar Radiation}

The simplest method for measuring the solar radiation is with a pyranometer, which measures the total solar radiation on a surface. Two types of pyranometers are in common use:

- Thermopile. This instrument consists of a series of TCs that detects a temperature difference caused by the solar radiation. The thermopile is the more accurate and more expensive of the two types.

- Photovoltaic. This instrument includes a PV cell, and the measurement is based on the electrical response of the cell to the solar radiation. The most common type of sensor uses a photodiode to measure the incident solar radiation. The output of the photodiode is not uniform across the solar spectrum, but the error is small. Because of this nonuniform response, these instruments are not recommended for use under artificial light, under plant canopies, or where there is significant reflected light. However, this less expensive type of instrument is adequate for completing this procedure.

The global horizontal solar radiation is the most useful measurement. Most simulation programs are written to use this value of solar radiation along with direct normal and horizontal diffuse, both of which can be estimated from the global horizontal value. If the measurement plan includes a PV system, measuring the solar radiation in the plane of the PV panels may be useful. If two pyranometers are available, both the global horizontal solar radiation and the PV plane solar radiation should be measured.

\section{References}

ASHRAE (2002). Measurement of Energy and Demand Savings. ASHRAE Guideline 14-2002. Atlanta, GA: American Society of Heating, Refrigerating and Air-Conditioning Engineers, Inc.

ASHRAE (2005). ASHRAE Handbook of Fundamentals. Atlanta, GA: American Society of Heating, Refrigerating and Air-Conditioning Engineers, Inc.

IPMVP (2002). International Performance Measurement and Verification Protocol Concepts and Options for Determining Energy and Water Savings. Volume I. DOE /GO-102002-1554. Available at www.ipmvp.org/info/downloads.html. (Accessed April 18, 2003.) Washington DC: U.S. Department of Energy. 


\section{Appendix C - Uncertainty Analysis}

\section{C.1 - Background}

Estimating uncertainty is an important step in data reduction and expression of results. This section introduces uncertainty analysis and provides an uncertainty analysis method for this procedure. The approach outlined here contains many simplifications from a rigorous uncertainty analysis. Our intent is to provide a practical approach without losing the essential uncertainty effects. This procedure is compatible with standard International and U.S. practices from the International Organization for Standardization (ISO 1995), National Institute of Standards and Technology (NIST 1994), American Society of Mechanical Engineers (ASME 1998), and the Instrument Society of America (Dieck 1997).

Uncertainty analysis in building monitoring projects is often neglected either because the practitioner knows that the uncertainty will be small, or because the practitioner does not know how to complete the uncertainty analysis and is overwhelmed by the complexities of rigorous uncertainty analysis. If the correct size instruments are used and they are installed and operated properly, the uncertainty is usually small and within the desired accuracy for building monitoring projects. Nevertheless, this does not relieve the practitioner from having to understanding error and uncertainty.

There is often confusion between uncertainty and error. Error is the difference between the true value, which we do not know, and the measured value; therefore, the error is unknowable. Uncertainty is an estimate of the limits of the error. The terms have different meanings and should not be confused. Every step in the process of making a measurement and reducing the data can introduce an error. The practitioner must be careful to recognize and minimize the sources of error to develop a reasonable estimate of the measurements' uncertainty.

Error is often described as having random and systematic components. The effects of random errors arise from unpredictable temporal or spatial variations in repeated observations of the measurand. All other errors are classified as systematic errors (also called bias errors). All errors should be minimized or adjusted for as practical by careful experimental design, sensor selection, sensor placement, calibration, data acquisition, and data reduction.

The ISO guideline divides uncertainty by the method used to determine it and not by the source. Type A evaluation of uncertainty is from statistical analysis of a series of observations, and Type B evaluation of uncertainty includes all other analysis that is not Type A. ASME (1998) and Dieck (1997) use a slightly different approach by dividing the uncertainties by the effect. Effects that cause scatter in the results are classified as random uncertainties; all others are systematic uncertainties. This procedure follows the ISO approach for classifying uncertainties, but applies the terms random and systematic to the Type A and Type B uncertainties.

Uncertainties are generally combined as the square root of the sum of the squares. The random and systematic uncertainties are treated separately, then combined to arrive at the final uncertainty. A coverage factor $k$ is sometimes used to provide the desired confidence interval. For example, the following uncertainties have coverage factors of 1.7 for $90 \%$ confidence and 2 for $95 \%$ confidence, and assume adequate degrees of freedom.

$$
\begin{aligned}
& \mathrm{U}_{90}=1.7\left[\mathrm{U}_{\mathrm{B}}^{2}+\mathrm{U}_{\mathrm{A}}^{2}\right]^{1 / 2} \\
& \mathrm{U}_{95}=2.0\left[\mathrm{U}_{\mathrm{B}}^{2}+\mathrm{U}_{\mathrm{A}}^{2}\right]^{1 / 2}
\end{aligned}
$$

These equations assume that (1) the uncertainties $U_{A}$ and $U_{B}$ have symmetric and normal distributions; (2) the uncertainties are at the standard deviation confidence level (68\% coverage); and (3) the uncertainties have a large degrees of freedom $(\geq 30)$. In this procedure, we make these assumptions unless we have 
specific information to the contrary. The value of the coverage factor $(\mathrm{k}=1.7)$ comes from the $\mathrm{t}-$ distribution for $90 \%$ confidence with a degree of freedom greater than 30 , as shown in Table C-10. The $90 \%$ confidence interval (sometimes stated as $90 \%$ coverage) means that 9 of 10 observations should satisfy $x=\bar{x} \pm U_{90}$. This procedure requires that uncertainties be reported at the $90 \%$ confidence level unless project requirements dictate otherwise. If the confidence levels of uncertainties from outside this procedure are not known, a knowledgeable estimate will have to be made.

Uncertainty analysis should be completed before (pretest) and after (posttest) a monitoring project. The purpose of the pretest uncertainty analysis is to determine whether the designed approach will fit within the accuracy and cost constraints of the monitoring project. The research plan may have to be altered to find the best balance between accuracy, cost, and effort. The uncertainty analysis should be repeated following the monitoring exercise with the actual sensor and measurement data to determine the uncertainty of the final result and whether the uncertainty is within the accuracy requirements. In addition, the pretest and posttest uncertainty analyses should be compared with each other and any major discrepancies corrected.

\section{C.2 - Uncertainty Analysis Procedure}

As every building energy-monitoring project is different, so is every uncertainty analysis. However, general steps should be followed, and Table C-1 provides an outline of an uncertainty analysis procedure. The procedure represents a balance between rigorous and practical approaches.

Table C-1 Uncertainty Analysis Procedure

\begin{tabular}{|c|c|}
\hline Step & Reference \\
\hline $\begin{array}{l}\text { 1. Define Measurement Problem } \\
\text { - List measurements, instruments, accuracies, and } \\
\text { equations used in analysis }\end{array}$ & \\
\hline $\begin{array}{l}\text { 2. Identify Error Sources } \\
\text { - List potential sources of error and estimated } \\
\text { uncertainties }\end{array}$ & $\begin{array}{l}\text { Table C-2 } \\
\text { Section C.5 }\end{array}$ \\
\hline $\begin{array}{l}\text { 3. List Uncertainties } \\
\text { - List uncertainties in a table format by type (random or } \\
\text { systematic) }\end{array}$ & Sections C.3, C.4, and C.5 \\
\hline $\begin{array}{l}\text { 4. Determine Sensitivity Coefficients } \\
\text { - Determine the sensitivity coefficients from functions } \\
\text { used in the analysis and enter in the table }\end{array}$ & $\begin{array}{l}\text { Section C. } 6 \\
\text { Equations C.6 and C.7 }\end{array}$ \\
\hline $\begin{array}{l}\text { 5. Determine the Degrees of Freedom and Coverage Factor } \\
\text { - List degrees of freedom in the table } \\
\text { - Determine the effective degrees of freedom } \\
\text { - Determine the desired coverage factor }\end{array}$ & $\begin{array}{l}\text { Section C.7 } \\
\text { Equations C.10 and C.11 } \\
\text { Table C-10 }\end{array}$ \\
\hline $\begin{array}{l}\text { 6. Combine the Uncertainties } \\
\text { - Combine random and systematic uncertainties } \\
\text { separately then combine and apply the appropriate } \\
\text { coverage factor }\end{array}$ & $\begin{array}{l}\text { Section C.6 } \\
\text { Equations C.8 and C.9 }\end{array}$ \\
\hline $\begin{array}{l}\text { 7. Report the Uncertainties } \\
\text { - Report the final result with the uncertainty and } \\
\text { confidence interval }\end{array}$ & \\
\hline
\end{tabular}




\section{C.3 - Random Uncertainty}

Unpredictable variation or scatter that is apparent in repeated observations of an event under the same conditions is called random error. Measurements in buildings are rarely repeated under constant conditions; however, random error may result from regression analysis or be assigned to sensor calibrations.

The uncertainty approximation of the random error in a sample of $\mathrm{n}$ observations is estimated from the sample standard deviation as in Equation C.3. Usually we are interested in the mean value of a sample of measurements, and the random uncertainty of the mean value is estimated as the standard deviation of the mean as given by Equation C.4. The sample standard deviation is the random uncertainty of each measurement; the standard deviation of the mean is the random uncertainty of the mean of all the measurements. The degree of freedom $v$ is equal to $n-1$.

$$
\begin{aligned}
& S_{\mathrm{x}}=\left[\sum_{\mathrm{i}=1}^{\mathrm{n}}\left(\mathrm{x}_{\mathrm{i}}-\overline{\mathrm{x}}\right)^{2} /(\mathrm{n}-1)\right]^{1 / 2} \\
& \mathrm{~S}_{\overline{\mathrm{x}}}=\mathrm{S}_{\mathrm{x}} / \sqrt{\mathrm{n}}
\end{aligned}
$$

Uncertainties from instrument calibration, data acquisition, and round off errors can also contribute to the random uncertainty. If the instrument calibration does not provide enough information to estimate the division between random and systematic uncertainty, this procedure assumes all uncertainty to be systematic.

Regression models are sometimes used to correlate measured energy variables with a driving force like outdoor dry-bulb temperature. The resulting function can be used to estimate energy data for periods when it was not measured. For example, the functional expression can be used to fill missing data or estimate data for periods outside the measurement period. However, the function should be used judiciously and not beyond the range of data used to determine the function.

The residual standard deviation $\mathrm{S}_{\mathrm{Y} / \mathrm{X}}$ is a measure of how well the function fits the measured data and is calculated as shown in Equation C.5 and Example C.9.4. However, it is not an absolute test of "fit" and can be misleading. Higher order relationships can sometimes provide a good fit to the data but contain oscillations between data points. A visual inspection of the function and the measured data can help determine how well the function fits the data.

$$
\mathrm{S}_{\mathrm{Y} / \mathrm{X}}=\left[\frac{\sum_{\mathrm{i}=1}^{\mathrm{n}}\left(\mathrm{y}_{\mathrm{i}}-\hat{\mathrm{y}}_{\mathrm{i}}\right)^{2}}{(\mathrm{n}-\mathrm{p})}\right]^{1 / 2}
$$

The measured dependent variables are $y_{i}$ and the function values are $\hat{y}_{i}$. The degrees of freedom is $v=(n$ $-\mathrm{p}$ ), where $\mathrm{n}$ is the number of observations used to determine the functional relationship and $\mathrm{p}$ is the number of parameters in the function. Section C.7 provides more discussion on degrees of freedom.

\section{C.4 - Systematic Uncertainty}

Systematic uncertainties are from all error sources that are not classified as random. Estimated values of the systematic uncertainties come from experience, engineering judgment, and careful analysis of the results. Instrument drift can increase the systematic uncertainty, which can be a problem for long-term monitoring projects. All instruments should be calibrated or replaced according to the manufacturers' recommendations, or sooner if problems are suspected. 
Most systematic uncertainties are assumed to have equal positive and negative magnitude and probability. Furthermore, unless more information is known, the systematic uncertainties are assumed to have a normal distribution and a 95\% confidence interval (ASME 1998). If more details are known, they should be used to handle the systematic uncertainties. If the calibration history is not well known, a more conservative approach is to assume $68 \%$ coverage $\left(\mathrm{U}_{\mathrm{B}}=\mathrm{s}\right)$. If the physical characteristics of the measurement dictate that the systematic uncertainties are not symmetric about the expected value, the positive and negative uncertainties should be calculated separately.

\section{C.5 - Uncertainty Sources}

The first goal of uncertainty analysis is to reduce the possible sources of uncertainty as much as practical. Grouping the sources of potential uncertainties is a helpful, but not necessary, step in uncertainty analysis. Grouping helps identify and track uncertainty sources. Table C-2 summarizes the sources of uncertainties and how to deal with them in this procedure. All standard uncertainties, either random $U_{A}$ or systematic $\mathrm{U}_{\mathrm{B}}$, are estimated at the level of confidence of the standard deviation. For a normal distribution, the standard deviation provides an uncertainty with a confidence interval of approximately $68 \%$ (i.e., $68 \%$ of the observations are expected to lie within $\bar{X} \pm S_{x}$ ).

Table C-2 Summary of Uncertainty Sources

\begin{tabular}{|c|c|c|c|c|}
\hline Source & Type & Uncertainty & $\begin{array}{l}\text { Degrees of } \\
\text { Freedom }\end{array}$ & Comments \\
\hline $\begin{array}{l}\text { Repeated } \\
\text { Observations }\end{array}$ & Random & $\mathrm{U}_{\mathrm{A}}=\mathrm{S}_{\overline{\mathrm{x}}}$ & $v=n-1$ & Equations C.3 and C.4 \\
\hline $\begin{array}{l}\text { Regression } \\
\text { Analysis }\end{array}$ & Random & $\mathrm{U}_{\mathrm{A}}=\mathrm{S}_{\mathrm{Y} / \mathrm{X}}$ & $v=n-p$ & Equation C.5 \\
\hline $\begin{array}{l}\text { Sensor } \\
\text { Calibration } \\
\text { Accuracy, s }\end{array}$ & Systematic & $U_{B}=S / 2$ & $v>30$ & $\begin{array}{l}\text { If there is confidence in the sensor and } \\
\text { the calibration, assume (1) symmetric } \\
\text { and normal distribution, (2) } 95 \% \\
\text { coverage, and (3) large degree of } \\
\text { freedom }(>30) \text {. }\end{array}$ \\
\hline $\begin{array}{l}\text { Sensor } \\
\text { Calibration } \\
\text { Accuracy, s }\end{array}$ & Systematic & $U_{B}=S$ & $v>30$ & $\begin{array}{l}\text { If there is limited confidence in and } \\
\text { information about the sensor calibration, } \\
\text { assume (1) symmetric and normal } \\
\text { distribution, (2) } 68 \% \text { coverage, and (3) } \\
\text { large degree of freedom (>30). }\end{array}$ \\
\hline $\begin{array}{l}\text { Sensor } \\
\text { Calibration } \\
\text { Accuracy, s }\end{array}$ & $\begin{array}{l}\text { Systematic } \\
\text { and } \\
\text { Random }\end{array}$ & $\begin{array}{l}\text { Estimate } \\
U_{A} \& U_{B} \\
\text { from } S\end{array}$ & & $\begin{array}{l}\text { If detailed information is known about the } \\
\text { sensor accuracy, it can be used to } \\
\text { estimate } U_{A}, U_{B} \text {, and } v \text {. }\end{array}$ \\
\hline $\begin{array}{l}\text { Resolution } \\
\text { and Round } \\
\text { Off Error }\end{array}$ & Systematic & $U_{B}=a / \sqrt{ } 3$ & $v \rightarrow \infty$ & $\begin{array}{l}\text { Assume (1) rectangular distribution with } \\
\text { equal probability and }(2) \text { half width of } \\
\text { distribution } a=\left(a^{-}+a^{+}\right) / 2 \text {. }\end{array}$ \\
\hline $\begin{array}{l}\text { Measurement } \\
\text { \& Analysis } \\
\text { Methods }\end{array}$ & Systematic & Estimated & $\begin{array}{l}\text { Equation } \\
\text { C. } 10\end{array}$ & $\begin{array}{l}\text { Uncertainty is based on best engineering } \\
\text { judgment and degrees of freedom is } \\
\text { based on an assumed reliability of the } \\
\text { estimated uncertainty. }\end{array}$ \\
\hline Other & & & & $\begin{array}{l}\text { Use best engineering judgment along } \\
\text { with other references where appropriate. }\end{array}$ \\
\hline
\end{tabular}


ASME (1998) and Dieck (1997) provide the following general uncertainty groups:

- $\quad$ Calibration uncertainties are from the limited precision of instruments. Instruments are calibrated to achieve a small combination of systematic uncertainty of the standard instrument and the random uncertainty of the comparison. The magnitude of this uncertainty can be obtained from the manufacturers' specifications or field calibrations. If there is not enough information to estimate the division between random and systematic uncertainty, this procedure assumes that all uncertainty is systematic. Most calibration uncertainties will be assumed to have symmetric and normal distributions and to have $95 \%$ coverage $\left(U_{B}=s / 2\right)$. If the calibration history is not well known, a more conservative approach is to assume $68 \%$ coverage $\left(U_{B}=s\right)$.

- $\quad$ Data acquisition uncertainties include limitations in sensing and recording signals, signal conditioning, and the sensors. These uncertainties can be reduced by overall measurement system field calibrations. The data logger error may be stated as a percent of the measurement at the data logger (usually a current or voltage). There may also be a resolution error when the analog signal is rounded off because only a limited number of digits can be stored and transmitted. These uncertainties also include those introduced by manual reading and recording data. Manually read meters sometimes have low resolution and can be misread.

- Data reduction uncertainties come from processing raw data. Computational round off errors are usually very small and are neglected. However, errors from curve fits to measured data can be significant. Regression models are often used to relate a dependent variable to independent variables, such as energy consumption to outdoor temperature. Regression models can be used to fill in missing data or extrapolate beyond the measurement period. The simplest estimate of the modeling uncertainty is given by the residual standard deviation as shown in Equation C.5. Uncertainty should also be estimated for all data from sources that are not directly measured.

- $\quad$ Uncertainties due to methods are from the techniques in the measurement process. Examples of these uncertainties include those embedded in calculations such as constants or material properties; obtrusive disturbance of a medium by the sensors; spatial averaging of discrete points; environmental effects such as convection, conduction, and radiation; and instability and hysteresis in the sensor. Installation effects should be minimized with careful planning and field calibration of the measurement systems. Even with careful placement, they represent the largest potential uncertainties for measurement of physical phenomena such as temperatures and fluid flows. For example, consider the temperature measurement of a fluid in a pipe by inserting a thermocouple (TC) probe in a thermal well in the pipe. Probe errors will result from thermal resistance between the fluid and the TC and from conduction along the thermal well and thermal couple to the surrounding environment. Spatial errors will result from measuring the fluid temperature in one spot in the pipe and assigning this value to be the average of all the fluid in the cross section of pipe. Another spatial error that may be significant is that the sensor may be at a different location along the length of the pipe relative to the desired point of measurement.

\section{C.6 - Combining Uncertainties}

In general, uncertainties are combined as the square root of the sum of the squares. To combine uncertainties, they must be at the same level of confidence. Combining uncertainties is usually done at the standard deviation level of confidence, which is 68\%. Random (Type A) and systematic (Type B) uncertainties should be summed separately until the end of the analysis.

The final result we are interested in is often derived from a function of measured and constant values such as $R=f\left(X_{1}, X_{2}, X_{3}, \ldots X_{m}\right)$. The effects of the uncertainty in each term (measured and constant) on the result are not the same. The most common approach to determine the relative effects of uncertainties on a result is by the use of a Taylor series expansion of the function. The first-order terms from the Taylor 
series expansion are the sensitivity coefficients. If the uncertainties are independent, the absolute $\theta_{\mathrm{i}}$ and relative $\theta_{\mathrm{i}}^{\prime}$ sensitivity coefficients can be calculated analytically or approximated numerically as shown in Equations C.6 and C.7.

$$
\begin{aligned}
& \theta_{\mathrm{i}}=\frac{\partial \mathrm{R}}{\partial \mathrm{X}_{\mathrm{i}}} \approx \frac{\Delta \mathrm{R}}{\Delta \mathrm{X}_{\mathrm{i}}} \\
& \theta_{\mathrm{i}}^{\prime}=\frac{\mathrm{X}_{\mathrm{i}}}{\mathrm{R}} \frac{\partial \mathrm{R}}{\partial \mathrm{X}_{\mathrm{i}}} \approx \frac{\mathrm{X}_{\mathrm{i}}}{\mathrm{R}} \frac{\Delta \mathrm{R}}{\Delta \mathrm{X}_{\mathrm{i}}}
\end{aligned}
$$

The uncertainties (treating random and systematic separate) of the result $\mathrm{R}$ can then be combined as

$$
U=\left[\sum_{i=1}^{n}\left(\theta_{i} U_{X_{i}}\right)^{2}\right]^{1 / 2}
$$

Finally, the combined uncertainty is the combination of the random and systematic uncertainties

$$
\mathrm{U}_{\mathrm{C}}=\mathrm{k}\left[\mathrm{U}_{\mathrm{B}}^{2}+\mathrm{U}_{\mathrm{A}}^{2}\right]^{1 / 2}
$$

Where $\mathrm{k}$ is the coverage factor that provides appropriate confidence interval $\mathrm{C}$ in the final expression of uncertainty. Section C.7 and Table C-10 provide more information about the coverage factor and degrees of freedom.

Equation C.8 assumes that the systematic uncertainties are independent. If the uncertainties are correlated, the covariance term from the Taylor series expansion should be included in the uncertainty calculations. The covariance term contains the cross products of the uncertainties and the sensitivity coefficients. ASME (1998) and ISO (1995) contain more information on correlated uncertainties.

\section{C.7 - Coverage Factor and Degrees of Freedom}

Dieck (1997) defines the degrees of freedom $v$ as the freedom left in a data set for error or variability. For example, in the calculation of the sample standard deviation $S_{x}$, the sample mean $\bar{x}$ is calculated, and one degree of freedom is lost, therefore $v=(n-1)$. In the calculation of the residual standard deviation from a regression curve fit, $v=(n-p)$, where $n$ is the number of measured observations used to establish the correlation and $\mathrm{p}$ is the number of constants determined in the correlation.

For building monitoring projects, some systematic uncertainties and the degrees of freedom must be estimated. The degrees of freedom can be thought of as a measure of how good the estimated uncertainty is (or more precisely, the estimated variance). The degrees of freedom can be estimated from the following equation (ISO 1995).

$$
\mathrm{v} \approx \frac{1}{2}\left[\frac{\Delta \mathrm{u}(\mathrm{x})}{\mathrm{u}(\mathrm{x})}\right]^{-2}
$$

The term in the brackets is the relative uncertainty of the estimated uncertainty $u(x)$. It can be thought of as the reliability of the estimated uncertainty $\mathrm{u}(\mathrm{x})$. For example, if an estimated uncertainty $\mathrm{u}(\mathrm{x})$ of an instrument is believed to be reliable to within $\pm 25 \%$ (or the relative uncertainty is $\pm 25 \%$ ), then $v \approx 1 / 2$ $(0.25)^{-2}=8$.

The degrees of freedom is used to determine the coverage factor $\mathrm{k}$, which is used to determine the uncertainty band for different confidence levels. For example, if the degrees of freedom are greater than 
30 and the data follow a normal distribution, the t-distribution for $95 \%$ confidence is approximately 2 and 1.7 for $90 \%$ confidence. Therefore, the data should lie within the bounds of $\bar{x} \pm 2 U 95 \%$ of the time. The t-distribution is shown in Table C-10 for different confidence levels (ASHRAE 2002 and ISO 1993).

Uncertainties calculated in this procedure should be estimated at a $90 \%$ confidence level unless requirements of the analysis call for a different level. The use of $90 \%$ confidence intervals for building energy measurements follows requirements in ASHRAE (2002) and IPMVP (2002) guidelines.

When two or more uncertainties are combined, the distribution can be approximated by the t-distribution with the effective degrees of freedom calculated by the Welch-Satterthwaite formula:

$$
v_{\text {eff }}=\frac{\left(\sum_{i=1}^{n} S_{i}^{2}\right)^{2}}{\sum_{i=1}^{n} \frac{S_{i}^{4}}{v_{i}}}
$$

Table C-3 t-Distribution

\begin{tabular}{|l|l|l|l|l|}
\hline $\begin{array}{c}\text { Degrees of } \\
\text { Freedom }\end{array}$ & $\begin{array}{c}\mathbf{6 8 \%} \\
\text { Confidence }\end{array}$ & $\begin{array}{c}\mathbf{8 0 \%} \\
\text { Confidence }\end{array}$ & $\begin{array}{c}\mathbf{9 0 \%} \\
\text { Confidence }\end{array}$ & $\begin{array}{c}\mathbf{9 5 \%} \\
\text { Confidence }\end{array}$ \\
\hline 1 & 1.84 & 3.08 & 6.31 & 12.71 \\
\hline 2 & 1.32 & 1.89 & 2.92 & 4.30 \\
\hline 3 & 1.20 & 1.64 & 2.35 & 3.18 \\
\hline 4 & 1.14 & 1.53 & 2.13 & 2.78 \\
\hline 5 & 1.11 & 1.48 & 2.02 & 2.57 \\
\hline 10 & 1 & 1.37 & 1.81 & 2.23 \\
\hline 15 & 1 & 1.34 & 1.75 & 2.13 \\
\hline 20 & 1 & 1.33 & 1.73 & 2.09 \\
\hline 25 & 1 & 1.32 & 1.71 & 2.06 \\
\hline$\geq 30$ & 1 & 1.3 & 1.7 & 2.0 \\
\hline$\infty$ & 1 & 1.28 & 1.65 & 1.96 \\
\hline
\end{tabular}

\section{C.8 - Definition of Terms}

Combined Uncertainty - $\left(\mathrm{U}_{\mathrm{c}}\right)$ Combination of all uncertainties, usually by the positive square root of the sum of the squares at confidence interval $\mathrm{c}$.

Covariance - A measure of the dependence of two random variables.

Coverage Factor - (k) multiplier used with the standard uncertainty to expand the uncertainty for the desired confidence. For example, the standard deviation is multiplied by a coverage factor of 2 for $95 \%$ confidence (or coverage), assuming that the degree of freedom is $\geq 30$. The coverage factor is typically based on the t-distribution (Table $\mathrm{C}-10$ ).

Error - The difference between the true value, which is not known, and the measured value.

Measurand - The quantity being measured.

Random Error - Error from unpredictable sources that are apparent in repeated observations. 
Random (Type A) Uncertainty - $\left(\mathrm{U}_{\mathrm{A}}\right)$ Uncertainty obtained from a statistical evaluation of a series of observations that form an observed probability density function.

Residual Standard Deviation - $\left(\mathrm{S}_{\mathrm{Y} / \mathrm{X}}\right)=$ An estimate of the scatter of data about a curve fit through the data. It is analogous to the standard deviation for the scatter of data about a mean.

Standard Deviation - $\left(\mathrm{S}_{\mathrm{x}}\right)$ A measure of the scatter of data about the mean equal to the positive square root of the variance. For a normal probability distribution and an infinite number of observations, approximately $68 \%$ of the observations will be contained in the interval $\bar{x} \pm S_{x}$. It is taken as the sample standard deviation (n-1 denominator) and not the population standard deviation (n denominator).

Standard Uncertainty $(\mathrm{U})$ - Uncertainty at the standard deviation level of confidence, which is $68 \%$.

Systematic Error - Error effects that are not attributed to random error. Systematic errors should be minimized through proper calibration and experimental design.

Systematic (Type B) Uncertainty - $\left(\mathrm{U}_{\mathrm{B}}\right)$ Uncertainty estimated by means other than statistical. This uncertainty is based on an assumed probability density function (e.g., normal, rectangular, or triangular).

Uncertainty - An estimation of the bounds of the error.

Variance - $\left(\mathrm{S}_{\mathrm{x}}{ }^{2}\right)$ A measure of dispersion equal to the sum of the square of the difference between the measurements and the mean divided by one less than the number of measurements.

\section{C.9 - Example Uncertainty Calculations}

\section{C.9.1 - Outdoor air dry-bulb temperature uncertainty}

Estimate the uncertainty in the measurement of the outdoor air dry-bulb temperature by a type-T shielded TC. The TC is connected to a data logger that contains a built-in thermistor reference temperature and calculates the temperature from the measured voltages. The temperature sensors are scanned every $15 \mathrm{~s}$ and the average value is recorded every $15 \mathrm{~min}$.

The significant error sources are sensor error, reference junction temperature sensor error, data acquisition error, and environmental errors. Uncertainties are assumed to be systematic with normal distributions, have $95 \%$ coverage (i.e., $U_{B}=U_{95} / 2$ ), and have a large degree of freedom $(\geq 30)$, unless otherwise noted.

- TC sensor uncertainty: Assume that the reference temperature junction is maintained at $20^{\circ} \mathrm{C}$ and the minimum $\mathrm{T}_{\mathrm{db}}$ is $-20^{\circ} \mathrm{C}$ for a maximum temperature differential of $-40^{\circ} \mathrm{C}$. The maximum error limits established by ANSI for Type-T TCs are $\pm 1.0^{\circ} \mathrm{C}$ from $-100^{\circ} \mathrm{C}$ to $100^{\circ} \mathrm{C}$ or $1.5 \%$, whichever is larger. However, practical experience has shown that this is extremely conservative for the midrange. A more reasonable estimation is to use $1.5 \% \times 40^{\circ} \mathrm{C}= \pm 0.6^{\circ} \mathrm{C}$. Therefore, $\mathrm{U}_{\mathrm{B}, \mathrm{I}}= \pm 0.6^{\circ} \mathrm{C} / 2= \pm 0.3^{\circ} \mathrm{C}$.

- Reference junction temperature uncertainty $= \pm 0.2^{\circ} \mathrm{C}$ (from data logger manufacturer). Therefore, $\mathrm{U}_{\mathrm{B}}$ $= \pm 0.2^{\circ} \mathrm{C} / 2= \pm 0.1^{\circ} \mathrm{C}$.

- TC polynomial voltage temperature conversion uncertainty $= \pm 0.001^{\circ} \mathrm{C}$ (data logger manufacturer). Therefore, $\mathrm{U}_{\mathrm{B}}= \pm 0.001^{\circ} \mathrm{C} / 2= \pm 0.0005^{\circ} \mathrm{C}$.

- Reference junction temperature to voltage conversion uncertainty $= \pm 0.001^{\circ} \mathrm{C}$ (data logger manufacturer). Therefore, $\mathrm{U}_{\mathrm{B}}= \pm 0.001^{\circ} \mathrm{C} / 2= \pm 0.0005^{\circ} \mathrm{C}$.

- Data acquisition voltage measurement uncertainty $= \pm 0.1 \%$ full scale reading (FSR) $= \pm 0.0025 \mathrm{mV}$ for $\pm 2.5 \mathrm{mV}$ range, which is $\pm 0.06^{\circ} \mathrm{C}$ at $45^{\circ} \mathrm{C}$ (from data logger manufacturer)

- Data acquisition resolution uncertainty $=0.00033 \mathrm{mV}$ for the $\pm 2.5 \mathrm{mV}$ range. This is much smaller than the other uncertainties and is neglected. 
- Environmental uncertainty is estimated from experience to be $\pm 0.5^{\circ} \mathrm{C}$ at $95 \%$ confidence with an estimated reliability of $25 \%$. The degrees of freedom from Equation C. 10 is $v=8$; therefore, the tstatistic for $95 \%$ is 2.3 and $\mathrm{U}_{\mathrm{B}}= \pm 0.5^{\circ} \mathrm{C} / 2.3=0.22$. The uncertainty is mainly due to radiation to the surroundings and convective thermal resistance around the TC.

Assuming that the uncertainties are uncorrelated, the maximum expected uncertainty in taking a single measurement is calculated in Table C-4. The effective degrees of freedom is calculated from Equation C. 11 to be 39 and the coverage factor for $90 \%$ confidence is 1.7 .

Table C-4 Uncertainty Analysis for a TC

\begin{tabular}{|l|l|l|l|l|l|}
\hline \multicolumn{1}{|c|}{$\begin{array}{c}\text { Uncertainty } \\
\text { Source }\end{array}$} & Units & $\begin{array}{c}\text { Standard } \\
\text { Systematic } \\
\text { Uncertainty } \\
\mathbf{U}_{\mathrm{B}}\end{array}$ & $\begin{array}{c}\text { Standard } \\
\text { Random } \\
\text { Uncertainty } \\
\mathbf{U}_{\mathrm{A}}\end{array}$ & $\begin{array}{c}\text { Degrees of } \\
\text { Freedom }\end{array}$ & $\begin{array}{l}\text { Sensitivity } \\
\text { Coefficient }\end{array}$ \\
\hline TC Limits of Error & ${ }^{\circ} \mathrm{C}$ & 0.3 & 0.0 & 30 & 1 \\
\hline Ref. Junction & ${ }^{\circ} \mathrm{C}$ & 0.1 & 0.0 & 30 & 1 \\
\hline TC Voltage Conversion & ${ }^{\circ} \mathrm{C}$ & 0.0005 & 0.0 & 30 & 1 \\
\hline Ref. Junction conversion & ${ }^{\circ} \mathrm{C}$ & 0.0005 & 0.0 & 30 & 1 \\
\hline TC Voltage Measurement & ${ }^{\circ} \mathrm{C}$ & 0.03 & 0.0 & 30 & 1 \\
\hline Environmental & ${ }^{\circ} \mathrm{C}$ & 0.22 & 0.0 & 8 & 1 \\
\hline & & Effective degrees of freedom $=$ & 39 & \\
\hline
\end{tabular}

\begin{tabular}{|l|l|l|l|l|}
\hline Uncertainty & Units & $\begin{array}{c}\text { Standard } \\
\text { Systematic } \\
\text { Uncertainty } \\
\sqrt{\sum\left(\theta \mathrm{U}_{\mathrm{B}}\right)_{\mathrm{i}}^{2}}\end{array}$ & $\begin{array}{c}\text { Standard } \\
\text { Random } \\
\text { Uncertainty }\end{array}$ & $\begin{array}{c}\text { Combined Uncertainty } \\
\sqrt{\sum\left(\theta \mathrm{U}_{\mathrm{A}}\right)_{\mathrm{i}}^{2}}\end{array}$ \\
\hline Thermocouple & ${ }^{\circ} \mathrm{C}$ & 0.39 & 0.0 & 0.66 \\
\hline
\end{tabular}

The uncertainty is therefore $\mathrm{U}_{90}= \pm 0.7^{\circ} \mathrm{C}$ with 41 degrees of freedom. Over the course of a long-term monitoring project, most of the temperature measurements would be within $20^{\circ} \mathrm{C}$ of the reference junction temperature, which would reduce the TC uncertainty to $\mathrm{U}_{95} \pm 0.3^{\circ} \mathrm{C}$ and the overall uncertainty, $\mathrm{U}_{90}= \pm 0.5^{\circ} \mathrm{C}$.

\section{C.9.2 - Electrical energy measurement uncertainty}

Calculate the uncertainty in electrical energy measurements made on a 480 VAC (phase-to-phase) threephase circuit with 100-amp current transformers (CTs) on each phase and a watt-hour meter (WHM). The CTs have a stated accuracy of $\pm 1 \%$ of the reading between $10 \%$ and $130 \%$ of rating, and the accuracy of the WHM is $\pm 0.45 \%$ of the reading $\pm 0.05 \%$ of full scale. The WHM output pulses with a full-scale frequency of $4 \mathrm{~Hz}$ and is connected to a pulse counter with a sampling frequency of $500 \mathrm{~Hz}$. A data logger scans the pulse counter every $15 \mathrm{~s}$. The WHM calculates the energy by the following equation

$$
E=\frac{n C T s \times V A C \times C T a m p s \times \text { Pulses }}{F S H z \times 3,600}
$$

where $\mathrm{E}$ is the energy in watt-hours, $\mathrm{nCT}$ s is the number of CTs, VAC is the phase to ground voltage (nominally $277 \mathrm{~V}$ ), CTamps is the average of the current passing through the nCTs, pulses is the number 
of pulses output, and FSHz is the full scale pulse frequency $(4 \mathrm{~Hz})$. The energy per pulse at full scale with three $100 \mathrm{amp}$ CTs is $5.771 \mathrm{Wh} /$ pulse.

The significant uncertainties are accuracies of the CTs and WHM. Errors associated with counting the pulses are small and are neglected. Errors in sensing the line voltage are assumed to be embedded in the accuracy of the WHM. The WHM uncertainty at full scale per pulse is calculated as the energy per pulse at full scale times the accuracy at full scale.

$$
U_{W H M, 95}= \pm \frac{3 \times 277 \times 100 \times 1}{4 \times 3,600} \times 0.50 \%= \pm 0.029 \mathrm{Wh} / \mathrm{pulse}
$$

The CT uncertainty is stated as a percentage of the current, and the sensitivity coefficient is calculated from Equation C.8.

$$
\begin{aligned}
& \mathrm{U}_{\mathrm{CT}, 95}=100 \times 0.01=1 \mathrm{~A} \\
& \theta_{C T}=\frac{\partial E}{\partial \text { CTamps }}=\frac{3 \times 277 \times 1}{4 \times 3,600}=0.0577 \mathrm{Wh} / \mathrm{pulse} / \mathrm{A}
\end{aligned}
$$

Both uncertainties are assumed to be systematic with normal distributions at $95 \%$ confidence and large degrees of freedom. Therefore, the standard uncertainty $U_{B}$ is found by dividing the uncertainties by a coverage factor of 2 . The coverage factor to have $90 \%$ confidence in the final result with $v \geq 30$ is 1.7 . The absolute and relative uncertainties are calculated in Table C-5.

Table C-5 Uncertainties for Electrical Energy Measurements

\begin{tabular}{|l|l|l|l|l|l|}
\hline \multicolumn{1}{|c|}{$\begin{array}{c}\text { Uncertainty } \\
\text { Source }\end{array}$} & \multicolumn{1}{|c|}{ Units } & $\begin{array}{c}\text { Standard } \\
\text { Systematic } \\
\text { Uncertainty } \\
\mathbf{U}_{\mathrm{B}}\end{array}$ & $\begin{array}{c}\text { Standard } \\
\text { Random } \\
\text { Uncertainty } \\
\mathbf{U}_{\mathrm{A}}\end{array}$ & $\begin{array}{l}\text { Degrees of } \\
\text { Freedom }\end{array}$ & $\begin{array}{l}\text { Sensitivity } \\
\text { Coefficient }\end{array}$ \\
\hline WHM (full scale 100 A) & Wh/pulse & 0.014 & 0.0 & 30 & 1 \\
\hline CT (full scale 100 A) & $\mathrm{A}$ & 0.5 & 0.0 & 30 & 0.0577 \\
\hline WHM (half scale 50 A) & Wh/pulse & 0.008 & 0.0 & 30 & 1 \\
\hline CT (half scale 50 A) & A & 0.25 & 0.0 & 30 & 0.0577 \\
\hline WHM (25 A) & Wh/pulse & 0.0005 & 0.0 & 30 & 1 \\
\hline CT (25 A) & A & 0.125 & 0.0 & 30 & 0.0577 \\
\hline
\end{tabular}

\begin{tabular}{|l|l|l|l|l|}
\hline \multicolumn{1}{|c|}{ Uncertainty } & \multicolumn{1}{|c|}{ Units } & $\begin{array}{c}\text { Standard } \\
\text { Systematic } \\
\text { Uncertainty } \\
\sqrt{\sum\left(\theta \mathrm{U}_{\mathrm{B}}\right)_{\mathrm{i}}^{2}}\end{array}$ & $\begin{array}{c}\text { Standard } \\
\text { Random } \\
\text { Uncertainty } \\
\sqrt{\sum\left(\theta \mathrm{U}_{\mathrm{A}}\right)_{\mathrm{i}}^{2}}\end{array}$ & \multicolumn{1}{|c|}{$\begin{array}{c}\text { Combined Uncertainty } \\
\mathrm{U}_{90}\end{array}$} \\
\hline Full scale 100 A & Wh/pulse & 0.0323 & 0.0 & 0.055 \\
\hline Half scale 50 A & Wh/pulse & 0.0165 & 0.0 & 0.028 \\
\hline Quarter scale 125 A & Wh/pulse & 0.0086 & 0.0 & 0.015 \\
\hline Full scale 100 A & $\%$ & $0.56 \%$ & 0.0 & $0.95 \%$ \\
\hline Half scale 50 A & $\%$ & $0.57 \%$ & 0.0 & $0.97 \%$ \\
\hline Quarter scale 125 A & $\%$ & $0.60 \%$ & 0.0 & $1.01 \%$ \\
\hline
\end{tabular}


The full-scale uncertainty is $\mathrm{U}_{90}= \pm 1 \%$ with 30 degrees of freedom, and the half-scale uncertainty is $\mathrm{U}_{90}$ $= \pm 1 \%$ with 30 degrees of freedom. The relative uncertainties apply to circuits using different sized CTs assuming the same WHM, number of CTs, and relative sensor accuracies.

This type of electrical meter would most likely be used to record 15-min or hourly total energy use, which then may also be condensed to daily, monthly, or yearly energy use. The uncertainty for the total energy measurement could be estimated in two ways: first by applying the relative uncertainties calculated above to the total energy, and second by combining the uncertainty per pulse for all the pulses in the total energy. For example, assume the energy total with an average of $50 \%$ power over $1 \mathrm{~h}$ is $24 \mathrm{kWh}$, which is 4,159 pulses. If we assume the uncertainty in the total energy is $1 \%, \mathrm{U}_{90}= \pm 240 \mathrm{Wh}$. By comparison, assuming the uncertainty per pulse is $\mathrm{U}_{90}= \pm 0.034 \mathrm{Wh}$, the uncertainty in the total is $\mathrm{U}_{90}=$ $\pm\left[4,159(0.028)^{2}\right]^{1 / 2}= \pm 1.8 \mathrm{Wh}$. The first method is more conservative and is recommended in this procedure.

\section{C.9.3 - Building energy use intensity uncertainty}

Estimate the uncertainty in the calculation of the annual site Building Energy Use Intensity (BEUI) of a building. The building electricity use is determined from a monitoring system similar to that used in Example C.9.2 and the gas use is from the utility bill. It is a two-story building with the gross interior floor area of $28,800 \mathrm{ft}^{2}$ as determined from the building drawings. The annual electricity use is $745.8 \times 10^{6}$ Btu and the annual gas use is $497.2 \times 10^{6}$ Btu.

We assume that the building dimensions are measured with an accuracy of $\pm 1 \mathrm{ft}$, and that this is a systematic uncertainty with a symmetric and normal probability distribution and $95 \%$ coverage. The uncertainty in the electricity total is assumed to be $\mathrm{U}_{68}= \pm 0.5 \%$ as determined in Example C.9.2 assuming an average of $50 \%$ power. The uncertainty in the gas measurements is based on at least three factors. The gas is billed on an energy content basis, which is determined by measuring the gas volume and multiplying by an energy multiplier. The energy multiplier is calculated monthly and depends on the energy content of the gas and the average outdoor air temperature. The accuracy of the gas meter is specified to be $\pm 2 \%$, which is typical for utility gas metering. This value is assumed to be a systematic uncertainty with a normal probability distribution and 95\% coverage and 30 degrees of freedom. The uncertainty in the energy multiplier is assumed to be $\pm 2 \%$ with $95 \%$ coverage, 30 degrees of freedom, and all systematic uncertainties. Finally, an uncertainty is associated with the difference in the energy multiplier and the actual energy content of the delivered gas. This uncertainty is estimated from the variation in the monthly values of the energy multiplier with temperature compensation term removed over a 3-yr period $(n=36)$. The uncertainty is estimated from the relative standard deviation of the monthly energy multiplier, which is $\mathrm{s}=0.8 \%$. The total uncertainty for the gas meter is $\mathrm{U}_{\mathrm{B}}=\left((2 / 2)^{2}+\right.$ $\left.(2 / 2)^{2}\right)^{1 / 2}=1.41 \%$ and $\mathrm{U}_{\mathrm{A}}=0.8 \%$.

\section{Building Area Uncertainty}

The building dimensions for each floor are length $=160 \pm 1 \mathrm{ft}$ and width $=90 \pm 1 \mathrm{ft}$. The area is calculated as $\mathrm{A}=2 \times \mathrm{L} \mathrm{x} \mathrm{W}$ (see Table C-6). 
Table C-6 Absolute Uncertainty for Building Area

\begin{tabular}{|l|l|l|l|l|l|}
\hline $\begin{array}{c}\text { Uncertainty } \\
\text { Source }\end{array}$ & Units & $\begin{array}{c}\text { Standard } \\
\text { Systematic } \\
\text { Uncertainty } \\
\mathbf{U}_{\mathrm{B}}\end{array}$ & $\begin{array}{c}\text { Standard } \\
\text { Random } \\
\text { Uncertainty } \\
\mathrm{U}_{\mathrm{A}}\end{array}$ & $\begin{array}{c}\text { Absolute } \\
\text { Sensitivity } \\
\theta_{\mathrm{i}}\end{array}$ & $\begin{array}{c}\text { Combined Uncertainty } \\
\mathrm{U}_{90}\end{array}$ \\
\hline Length & $\mathrm{ft}$ & 0.5 & 0 & $2 \times \mathrm{W}=180$ & $1.7 \sqrt{\sum\left(\theta_{\mathrm{i}} \mathrm{U}_{\mathrm{Bi}}\right)^{2}+\sum\left(\theta_{\mathrm{i}} \mathrm{U}_{\mathrm{Ai}}\right)^{2}}$ \\
\hline Width & $\mathrm{ft}$ & 0.5 & 0 & $2 \times \mathrm{L}=320$ & \\
\hline Total & $\mathrm{ft}^{2}$ & & & & $312 \approx 1 \%$ \\
\hline
\end{tabular}

\section{Building Energy Use Intensity Uncertainty}

The BEUI is calculated from BUEI $=\left(E_{\text {elec }}+E_{\text {gas }}\right) / A$ (see Table C-7).

Table C-7 Absolute Uncertainty for BEUI

\begin{tabular}{|l|l|l|l|l|l|l|}
\hline $\begin{array}{l}\text { Uncertainty } \\
\text { Source }\end{array}$ & Unit & $\begin{array}{c}\text { Nom. } \\
\text { Value }\end{array}$ & $\begin{array}{c}\text { Standard } \\
\text { Systematic } \\
\text { Uncertainty } \\
\mathrm{U}_{\mathrm{B}}\end{array}$ & $\begin{array}{c}\text { Standard } \\
\text { Random } \\
\text { Uncertainty } \\
\mathbf{U}_{\mathrm{A}}\end{array}$ & $\begin{array}{c}\text { Absolute } \\
\text { Sensitivity } \\
\theta_{\mathrm{i}}\end{array}$ & \multicolumn{1}{c|}{$\begin{array}{c}\text { Combined Uncertainty } \\
\mathrm{U}_{90}\end{array}$} \\
\hline \hline Area & $\mathrm{ft}^{2}$ & 28,800 & 273 & 0 & $\begin{array}{l}-\mathrm{E} / \mathrm{A}^{2}=- \\
1.499 \mathrm{E}-03\end{array}$ & \\
\hline $\begin{array}{l}\text { Electric } \\
\text { Energy }\end{array}$ & $\mathrm{kBtu}\left(\theta_{\mathrm{i}} \mathrm{U}_{\mathrm{Bi}}\right)^{2}+\sum\left(\theta_{\mathrm{i}} \mathrm{U}_{\mathrm{Ai}}\right)^{2}$ \\
\hline $\begin{array}{l}\text { Gas } \\
\text { Energy }\end{array}$ & $\mathrm{kBtu}$ & 495,800 & 3,729 & 0 & $\begin{array}{l}1 / \mathrm{A}= \\
3.4722 \mathrm{E}-05\end{array}$ & \\
\hline BEUI & $\mathrm{kBtu} / \mathrm{fan}$ & 7,011 & 3,978 & $\begin{array}{l}1 / \mathrm{A}= \\
3.4722 \mathrm{E}-05\end{array}$ & \\
\hline
\end{tabular}

Therefore, the BEUI $=43 \pm 0.9 \mathrm{kBtu} / \mathrm{ft}^{2}$ ( $90 \%$ coverage). More than half of this uncertainty comes from the area measurement.

\section{C.9.4 - Uncertainty of estimated data}

In an all-electric office building, the major end uses (heating, ventilating, and air-conditioning [HVAC], lights, and plug loads) are submetered every $15 \mathrm{~min}$ for 1 month with the same type of electrical meter system as that used in Example C.9.2. The on-site weather conditions (dry-bulb temperature, RH, and global horizontal solar radiation) are also measured on the same time interval. The electrical monitoring system was down for 9 days in the middle of a month; however, the weather data were recorded for the entire month. The building operating schedule is consistent for weekdays and weekends according to the light and plug load energy use. The HVAC controls did not change during this period. The weekday and weekend control settings for the HVAC systems are very different, so they should be treated separately. The measured dry-bulb temperature and HVAC energy is shown in Table C-10. The missing measured data (shown shaded) are filled with the linear regression formula.

Estimate the weekday HVAC energy consumption for the month by filling in the missing data.

The missing data can be estimated by multiplying the average of the measured daily energy use by the number of missing days, or from a linear regression between the daily HVAC energy use and the daily 
outdoor dry-bulb temperature. Both methods will be completed here for comparison. There are 23 weekdays during the month and 16 weekdays of good data; therefore, there are 7 days of missing energy data. The total energy for the 16 days of measured data is $6,598 \mathrm{kWh}$.

Method \#1 - Average daily energy use

From the weekday measured energy data, the average daily HVAC energy is $E_{\text {avg }}=412.4 \mathrm{kWh}$ with a standard deviation of $35.0 \mathrm{kWh}$ (Equation C.3). The average value was used to fill in the days of missing data to give a 7 day total of $2,887 \mathrm{kWh}$ and a monthly weekday (23 day) total of 9,485 $\mathrm{kWh}$. The random uncertainty for the sum of the 7 days is $\mathrm{U}_{\mathrm{A}-68}=\left[7 \mathrm{x}(35)^{2}\right]^{1 / 2}=92.6 \mathrm{kWh}$. The systematic uncertainty is taken from Example C.9.2 to be $\mathrm{U}_{\mathrm{B}-68}= \pm 0.5 \%$ assuming an average of $50 \%$ power for the whole 23 days. Assuming the degrees of freedom is 30 for the systematic uncertainty and 15 for the random uncertainty, the effective degrees of freedom from Equation C. 11 is 23 . The coverage factor for $90 \%$ confidence is 1.71 .

Table C-8 Uncertainty for Filling Data with Averaging

\begin{tabular}{|c|c|c|c|c|c|}
\hline $\begin{array}{l}\text { Uncertainty } \\
\text { Source }\end{array}$ & Units & $\begin{array}{c}\text { Standard } \\
\text { Systematic } \\
\text { Uncertainty } \\
U_{\mathrm{B}} \\
\end{array}$ & $\begin{array}{c}\text { Standard } \\
\text { Random } \\
\text { Uncertainty } \\
\mathbf{U}_{\mathbf{A}} \\
\end{array}$ & $\begin{array}{l}\text { Degrees of } \\
\text { Freedom }\end{array}$ & $\begin{array}{l}\text { Sensitivity } \\
\text { Coefficient }\end{array}$ \\
\hline Regression Analysis & kWh & 0 & 92.6 & 15 & 1 \\
\hline WHM & kWh & 46.3 & 0.0 & 30 & 1 \\
\hline \multicolumn{4}{|c|}{ Effective degrees of freedom $=$} & 23 & \\
\hline
\end{tabular}

\begin{tabular}{|l|l|l|l|l|}
\hline \multicolumn{1}{|c|}{ Uncertainty } & Units & $\begin{array}{c}\text { Standard } \\
\text { Systematic } \\
\text { Uncertainty } \\
\sqrt{\sum\left(\theta \mathrm{U}_{\mathrm{B}}\right)_{\mathrm{i}}^{2}}\end{array}$ & $\begin{array}{c}\text { Standard } \\
\text { Random } \\
\text { Uncertainty }\end{array}$ & $\begin{array}{c}\text { Combined Uncertainty } \\
\mathbf{U}_{90}\end{array}$ \\
\hline Monthly Total & $\mathrm{kWh}$ & 46.3 & 92.6 & $171 \sqrt{\sum\left(\mathrm{U}_{\mathrm{A}}\right)_{\mathrm{i}}^{2}}$
\end{tabular}

The total weekday HVAC energy use for the month is estimated by the averaging method to be

$$
\mathrm{E}=9,485 \pm 177 \mathrm{kWh} \text { at } 90 \% \text { confidence }
$$

Method \#2 - Linear regression of daily HVAC energy and outdoor temperature The linear regression of the daily HVAC energy use with daily average outdoor temperature produces the function $\mathrm{E}=5.357 \mathrm{~T}_{\mathrm{db}}+27.23$ as shown in Figure $\mathrm{C}$-1, which gives an estimated total for the 7 missing days of $\mathrm{E}=2,790 \mathrm{kWh}$. The residual standard deviation for estimating 1 day of energy use is calculated from Equation C. 5 to be $24.2 \mathrm{kWh}$. The random uncertainty for the sum of the 7 days is $\mathrm{U}_{\mathrm{A}-68}=[7 \mathrm{x}$ $\left.(24.2)^{2}\right]^{1 / 2}=64.1 \mathrm{kWh}$. The systematic uncertainty is taken from Example C.9.2 to be $U_{\mathrm{B}-68}= \pm 0.5 \%$ assuming an average of 50\% power for all 23 days. There are 14 degrees of freedom (16 days of data minus 2 parameters in the linear regression formula) for the random uncertainty and 30 for the systematic uncertainty. Before applying the linear regression formula, the average daily temperature for the days of missing energy data is verified to be within the range of average daily temperatures for the days with measured energy data. One day is $1.5^{\circ} \mathrm{F}$ cooler than the lowest daily temperature in the measured data set, and one day is $1.2^{\circ} \mathrm{F}$ warmer than the highest daily temperature in the measured data set. These two 
days are only slightly outside the range of data used in the regression, and the building systems should have the same operating characteristics at these temperatures. Therefore, the error should be within the uncertainty bounds.

Table C-9 Uncertainty for Filling Data with Regression Analysis

\begin{tabular}{|l|l|l|l|l|l|}
\hline \multicolumn{1}{|c|}{$\begin{array}{c}\text { Uncertainty } \\
\text { Source }\end{array}$} & Units & $\begin{array}{c}\text { Standard } \\
\text { Systematic } \\
\text { Uncertainty } \\
\mathbf{U}_{\mathbf{B}}\end{array}$ & $\begin{array}{c}\text { Standard } \\
\text { Random } \\
\text { Uncertainty } \\
\mathbf{U}_{\mathbf{A}}\end{array}$ & $\begin{array}{c}\text { Degrees of } \\
\text { Freedom }\end{array}$ & $\begin{array}{l}\text { Sensitivity } \\
\text { Coefficient }\end{array}$ \\
\hline Regression Analysis & $\mathrm{kWh}$ & 0 & 64.0 & 14 & 1 \\
\hline WHM & $\mathrm{kWh}$ & 46.9 & 0.0 & 30 & 1 \\
\hline \multicolumn{7}{|r|}{ Effective degrees of freedom $=$} & 29 & \\
\hline
\end{tabular}

\begin{tabular}{|l|l|l|l|l|}
\hline Uncertainty & Units & $\begin{array}{c}\text { Standard } \\
\text { Systematic } \\
\text { Uncertainty }\end{array}$ & $\begin{array}{c}\text { Standard } \\
\text { Random } \\
\text { Uncertainty }\end{array}$ & $\begin{array}{c}\text { Combined Uncertainty } \\
\mathbf{U}_{\mathbf{9 0}}\end{array}$ \\
& $\sqrt{\sum\left(\theta \mathrm{U}_{\mathrm{B}}\right)_{\mathrm{i}}^{2}}$ & $\sqrt{\sum\left(\theta \mathrm{U}_{\mathrm{A}}\right)_{\mathrm{i}}^{2}}$ & $1.7 \sqrt{\sum\left(\mathrm{U}_{\mathrm{B}}\right)^{2}+\sum\left(\mathrm{U}_{\mathrm{A}}\right)^{2}}$ \\
\hline Monthly Total & $\mathrm{kWh}$ & 46.9 & 64.0 & 135 \\
\hline
\end{tabular}

$\mathrm{E}_{\text {reg }}=9,405 \pm 135 \mathrm{kWh}$ at $90 \%$ confidence

The uncertainty from the regression method is smaller than from the averaging method, which is expected because the averaging method does not account for weather variations. The difference in total energy between the two methods is $80 \mathrm{kWh}$, which is within the uncertainty bounds of the both methods.

Table C-10 Dry-Bulb Temperature and HVAC Energy (Filled Data Are Shaded)

\begin{tabular}{|l|l|l|l|l|}
\hline \multicolumn{1}{|c|}{$\mathbf{T}\left({ }^{\circ} \mathbf{F}\right)$} & \multicolumn{1}{|c|}{$\mathbf{~ ( k W h )}$} & & \multicolumn{1}{|c|}{$\mathbf{T}\left({ }^{\circ} \mathbf{F}\right)$} & $\mathbf{E}(\mathbf{k W h})$ \\
\hline 75.2 & 462.5 & & 76.1 & 422.5 \\
\hline 75.4 & 430.3 & 75.2 & 411.0 \\
\hline 77.0 & 438.5 & 73.3 & 451.8 \\
\hline 77.9 & 433.3 & 69.7 & 416.5 \\
\hline 72.0 & 465.0 & 71.0 & 373.5 \\
\hline 63.7 & 369.7 & 75.1 & 401.5 \\
\hline 60.5 & 352.0 & & 70.9 & 397.0 \\
\hline 62.8 & 364.8 & & 67.6 & 403.3 \\
\hline 68.2 & 393.5 & & 69.9 & 388.8 \\
\hline 73.9 & 424.0 & & 62.0 & 356.3 \\
\hline 75.7 & 433.9 & & 62.0 & 346.5 \\
\hline 79.2 & 452.6 & & & \\
\hline
\end{tabular}




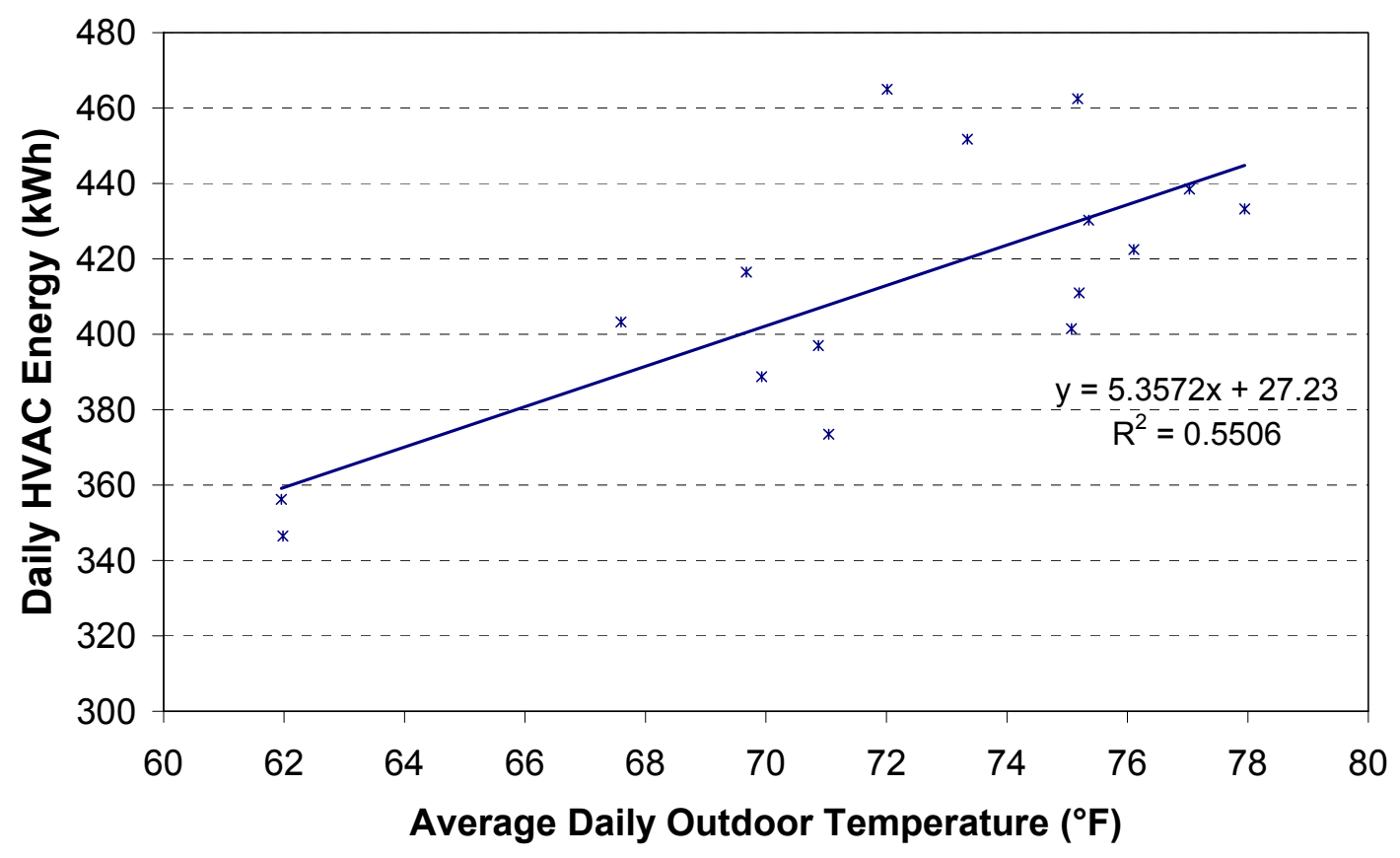

Figure C-1 Linear regression of daily HVAC energy and average daily outdoor temperature

\section{References}

ASHRAE (2002). Measurement of Energy and Demand Savings. ASHRAE Guideline 14-2002. Atlanta, GA: American Society of Heating, Refrigerating and Air-Conditioning Engineers, Inc.

ASME (1998). Test Uncertainty: Instruments and Apparatus. ASME Standard PTC 19.1-98. New York, NY: American Society of Mechanical Engineers.

Dieck, R.H. (1997). Measurement Uncertainty, Methods and Applications, Second ed. Research Triangle Park, NC: Instrument Society of America.

ISO (1995). Guide to the Expression of Uncertainty in Measurement. ISBN 92-67-10188-9. Geneva, Switzerland: International Organization for Standardization.

IPMVP (2002). Concepts and Options for Determining Energy and Water Savings. Volume I. International Performance Measurement and Verification Protocol, DOE/GO-102002-1554. Washington D.C.: U.S. Department of Energy. www.ipmvp.org. (Accessed April 18, 2003.)

NIST (1994). Guidelines for Evaluating and Expressing the Uncertainty of NIST Measurement Results. NIST Technical Note 1297, 1994 Edition. Gaithersburg, MD: National Institute for Standards and Technology. 


\section{Appendix D - Type 2 Grid-Tied System with Battery Backup}

The only difference between a Type 2 system and a Type 1 system is the battery component to the PV system. Batteries may be integrated into the DC side of the PV system for UPS applications or for other related building energy use applications (such as peak demand shaving).

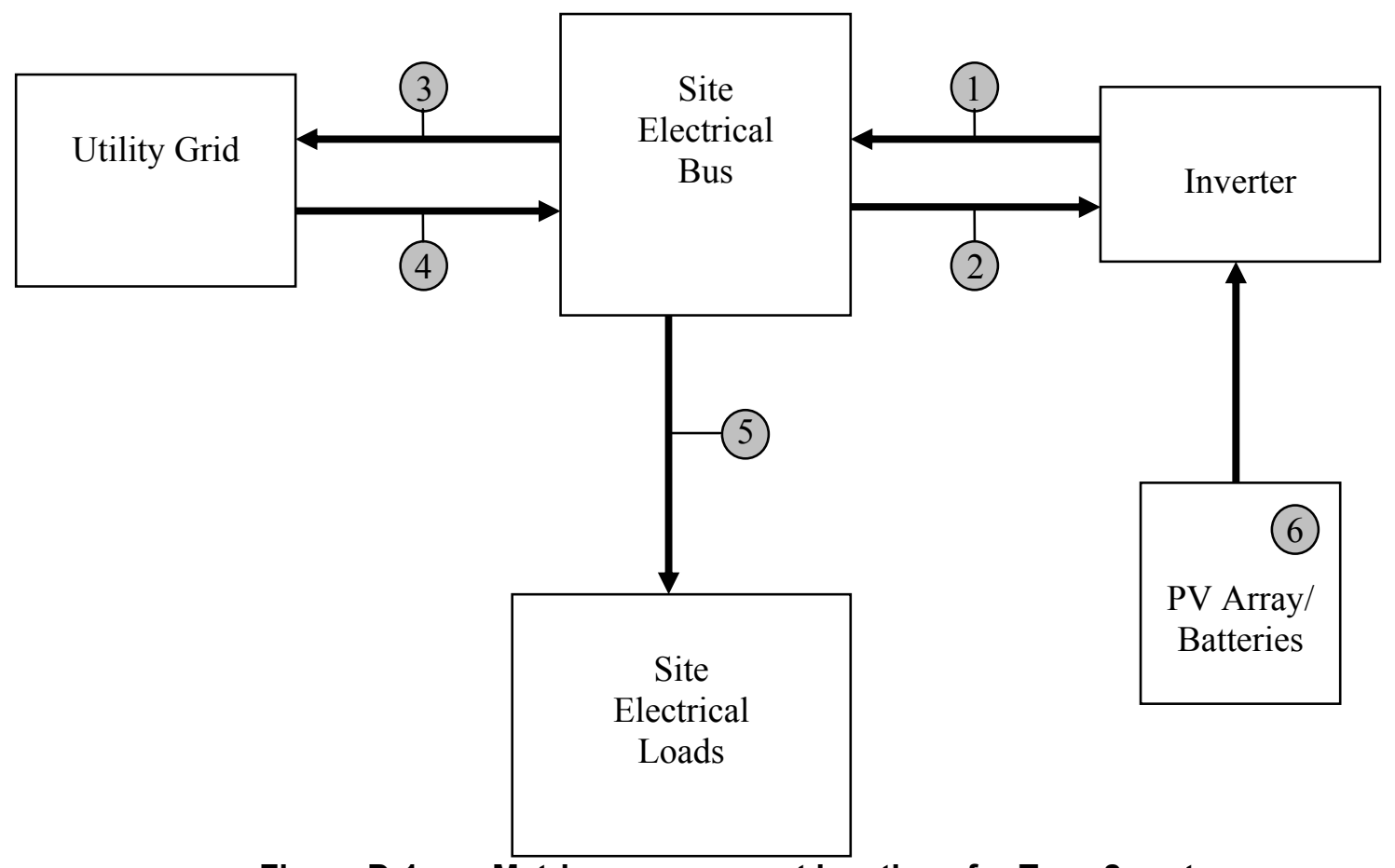

Figure D-1 Metric measurement locations for Type 2 system

Table D-1 Metrics in Type 2 Grid-Tied System

\begin{tabular}{|l|l|}
\hline $\begin{array}{c}\text { Type 2 } \\
\text { System } \\
\text { Meter \# }\end{array}$ & \multicolumn{1}{c|}{ Metric and Labels } \\
\hline 1 & $\begin{array}{l}\text { Total PV System Production and Back Up } \\
\text { Emergency Supply }\end{array}$ \\
\hline 2 & PV System Stand By and UPS Use \\
\hline 1 minus 2 & Net PV System Production \\
\hline 3 & Total Electricity Delivered To the Utility \\
\hline 4 & Total Electricity Consumed From the Utility \\
\hline 4 minus 3 & Net Facility Electricity Purchased from Utility \\
\hline 5 & Total Facility Electricity Use \\
\hline 6 & Incident Solar Radiation \\
\hline
\end{tabular}




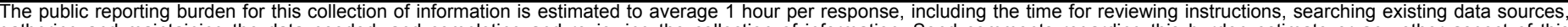

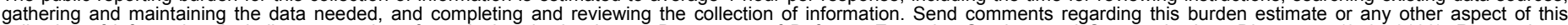

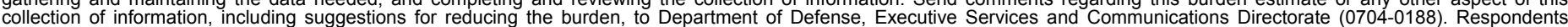

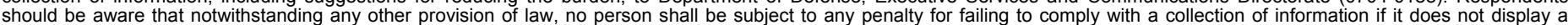

currently valid OMB control number.

PLEASE DO NOT RETURN YOUR FORM TO THE ABOVE ORGANIZATION.

\begin{tabular}{l|l|l} 
1. $\begin{array}{l}\text { REPORT DATE }(D D-M M-Y Y Y Y) \\
\text { October } 2005\end{array}$ & 2. $\begin{array}{l}\text { REPORT TYPE } \\
\text { Technical report }\end{array}$ & $\begin{array}{l}\text { 3. } \\
\text { DATES COVERED (From - To) } \\
2004-2005\end{array}$ \\
\hline
\end{tabular}

4. TITLE AND SUBTITLE

Procedure for Measuring and Reporting the Performance of

Photovoltaic Systems in Buildings 5a. CONTRACT NUMBER

DE-AC36-99-GO10337

5b. GRANT NUMBER

5c. PROGRAM ELEMENT NUMBER

5d. PROJECT NUMBER

NREL/TP-550-38603

5e. TASK NUMBER

BEC3.3002

5f. WORK UNIT NUMBER
7. PERFORMING ORGANIZATION NAME(S) AND ADDRESS(ES)

National Renewable Energy Laboratory

1617 Cole Blvd.

Golden, CO 80401-3393
8. PERFORMING ORGANIZATION REPORT NUMBER

NREL/TP-550-38603

9. SPONSORING/MONITORING AGENCY NAME(S) AND ADDRESS(ES)

10. SPONSOR/MONITOR'S ACRONYM(S) NREL

11. SPONSORING/MONITORING AGENCY REPORT NUMBER

12. DISTRIBUTION AVAILABILITY STATEMENT

National Technical Information Service

U.S. Department of Commerce

5285 Port Royal Road

Springfield, VA 22161

13. SUPPLEMENTARY NOTES

14. ABSTRACT (Maximum 200 Words)

This procedure provides a standard method for measuring and characterizing the long-term energy performance of photovoltaic (PV) systems in buildings and the resulting implications to the building's energy use. The performance metrics determined here may be compared against benchmarks for evaluating system performance and verifying that performance targets have been achieved. Uses may include comparison of performance with the design intent; comparison with other PV systems in buildings; economic analysis of PV systems in buildings; and the establishment of long-term performance records that enable maintenance staff to monitor trends in energy performance.

15. SUBJECT TERMS

performance metrics; building energy analysis; building energy performance; measurement and characterization; energy consumption; commercial buildings; photovoltaics; PV; PV and energy use.

\begin{tabular}{l|l|l|l|l|}
\hline $\begin{array}{l}\text { 16. SECURITY CLASSIFICATION OF: } \\
\begin{array}{l}\text { a. REPORT } \\
\text { Unclassified }\end{array}\end{array}$ & $\begin{array}{c}\text { b. ABSTRACT } \\
\text { Unclassified }\end{array}$ & $\begin{array}{l}\text { c. THIS PAGE } \\
\text { Unclassified }\end{array}$ & $\begin{array}{c}\text { LIMITATION } \\
\text { OF ABSTRACT } \\
\text { UL }\end{array}$ & $\begin{array}{c}\text { 18. NUMBER } \\
\text { OF PAGES }\end{array}$ \\
\hline
\end{tabular}
19a. NAME OF RESPONSIBLE PERSON 19b. TELEPHONE NUMBER (Include area code) 